NBER WORKING PAPER SERIES

\title{
RESOURCE CONCENTRATION AND CIVIL WARS
}

\author{
Massimo Morelli \\ Dominic Rohner \\ Working Paper 20129 \\ http://www.nber.org/papers/w20129 \\ NATIONAL BUREAU OF ECONOMIC RESEARCH \\ 1050 Massachusetts Avenue \\ Cambridge, MA 02138 \\ May 2014
}

An earlier version of this paper has circulated under the title "Natural Resource Distribution and Multiple Forms of Civil War". We wish to thank Peter Van der Windt and David Schoenholzer for excellent research assistance and Dawn Brancati, Lars-Erik Cederman, Oeindrila Dube, Tanisha Fazal, Benedikt Goderis, Matt Jackson, Cathy Hafer, John Huber, Päivi Lujala, Egil Matsen, Guy Michaels, Kalle Moene, Robert Powell, Rick van der Ploeg, Petros Sekeris, Jonathan Temple, Mathias Thoenig, Ragnar Torvik, Nicolas van de Sijpe, Peter van der Windt, Fabrizio Zilibotti and seminar and workshop participants in Washington University St. Louis, Geneva, Zurich, Columbia, Bristol, Oxford, York, Purdue, London School of Economics, Gerzensee, Trondheim, UC Berkeley, Mannheim, Namur, Rotterdam, Seattle (APSA), Milano Bicocca, Oslo, Barcelona Summer Forum, and Montpellier for helpful discussions and comments. The usual disclaimer applies. The views expressed herein are those of the authors and do not necessarily reflect the views of the National Bureau of Economic Research.

NBER working papers are circulated for discussion and comment purposes. They have not been peerreviewed or been subject to the review by the NBER Board of Directors that accompanies official NBER publications.

(C) 2014 by Massimo Morelli and Dominic Rohner. All rights reserved. Short sections of text, not to exceed two paragraphs, may be quoted without explicit permission provided that full credit, including (C) notice, is given to the source. 
Resource Concentration and Civil Wars

Massimo Morelli and Dominic Rohner

NBER Working Paper No. 20129

May 2014

JEL No. D74,O12,Q34

\title{
ABSTRACT
}

This paper highlights the importance of natural resource concentration and ethnic group regional concentration for ethnic conflict. A new type of bargaining failure due to multiple types of potential conflicts (and hence multiple threat points) is identified. The theory predicts war to be more likely when resource and group concentration are high, and the empirical analysis, both at the country level and at the ethnic group level, confirms the essential role of geographic concentration variables for civil war.

\author{
Massimo Morelli \\ Columbia University \\ Department of Economics \\ 420 West 118th Street, 720 IAB \\ New York, NY 10027 \\ and NBER \\ mm3331@columbia.edu \\ Dominic Rohner \\ Department of Economics \\ University of Lausanne \\ Quartier UNIL-Dorigny \\ Internef 551 \\ CH-1015 Lausanne \\ Switzerland \\ dominic.rohner@unil.ch
}




\section{Introduction}

This paper provides a novel theoretical explanation and novel empirical investigation of the importance of the geography of natural resources for civil war. We provide a new theoretical explanation for why civil wars occur with greater frequency when resource rents and ethnic divisions are both involved, and we do so without assuming any standard friction in the bargaining process. The prediction of the theory is that civil wars should be more frequent when the homeland of a minority group is particularly rich in resources, a prediction consistent with similar observations made before in the literature, but never obtained as equilibrium prediction of a frictionless bargaining game. The paper will then test the predictions and the mechanism of the theory on a number of data sets, providing also novel results on the quantitative importance of such concentration variables.

\section{Motivation and preview for the theory}

Two things seem to matter in general for civil war incentives: balance of strength and balance of control on resources. When trying to resolve a conflict between two groups over control of resources, one difficulty is that the relative strength of the two groups may differ from the relative wealth of natural resources of the territories they occupy. Pushing the power sharing towards making it reflect relative strength (strength proportionality) eliminates the incentives to "all-out" wars, but "secessionist" wars could then materialize; on the other hand, making power sharing depend on the groups' relative endowments of natural resources avoids secession tensions but may cause incentives for the majority group to use their strength to gain more power.

Recognizing this tension between the two most important determinants of bargaining power, we have decided to focus attention on a connected observation about bargaining games: while in a standard bargaining game there is a unique "threat point" (for example a unique type of war that players could fall into if bargaining breaks down), in reality there are multiple threat points, which depend on the balance of strength and geographic distribution of natural resources. If an ethnic group is particularly influential for the government of a country but another group has an important presence (in terms of population size and rootage to the territory) in a region of the country that is particularly rich in terms of natural resources, the tensions between the two criteria of power sharing mentioned above are maximized, and are exacerbated by the fact that the two groups have access to different threats: the powerful group controlling government forces should typically be stronger in an all-out ethnic conflict, but the minority group could sustain the secession threat with guerrilla war and focus its lower total strength on the defense of the area where it is locally stronger. 
We model these tensions in the following way: in a country divided into two regions and populated by two major groups, we assume that the stronger group nationally has a realistic advantage in all-out conflict, while a minority group mostly concentrated in one region has a probability of winning in a secessionist civil war that exceeds, for multiple reasons (discussed below), the probability of winning in an all-out civil war. Even though there are no frictions limiting bargaining on how to share the rents of natural resources, we show that peace may be impossible to guarantee, due to the possibility for the two main players to trigger two different threats. ${ }^{1}$ The characterization of the set of parameters where bargaining fails yields the prediction that the most conflict prone situations are those in which the mineral resources of value are mostly concentrated in the minority group region, and the risk is especially high in case of low State capacity, high regional concentration of the minority group in question, and large geographic distance of the minority region from the capital.

\section{Anecdotal motivation and preview of the empirical analysis}

When the presence of a local ethnic group coincides with large natural resource abundance concentrated in its region, this local ethnic group could be financially better off if it were independent and may under some conditions have incentives to start secessionist rebellion. This corresponds for example to the separatist movement in the now independent Timor-Leste, and the recent turmoil in the oil-abundant regions of Nigeria. Also the rebellion of the Aceh Freedom Movement in Indonesia starting in 1976 and the armed fight of the Sudan People's Liberation Army beginning in 1983 can to a large extent be explained by the abundance of natural resources in these separatist regions. ${ }^{2}$ Other countries where secessionist movements have been linked to large local natural resources include Angola, Myanmar, Democratic Republic of Congo, Morocco and Papua New Guinea. In all these cases an uneven natural resource distribution has been amplified by ethnic divisions. In contrast, if natural resources are absent or if natural resources (and political power) are evenly dispersed in a country, there are typically fewer conflictual incentives, even when there are ethnic divisions. ${ }^{3}$ Similarly, when there are large amounts of natural resources available, but the society is ethnically homogeneous, war incentives are weak. ${ }^{4}$

\footnotetext{
${ }^{1}$ It is easy to see - results available upon request - that if we add to our new source of bargaining failure one of the traditional ones, like asymmetric information about the other player's strength or on the probability of winning in general, the main results on the role of resource concentration and group concentration are unaltered. However, those traditional sources of bargaining frictions alone, without the multiplicity of threat points, do not suffice to explain the interaction effect of resource concentration and group concentration explained below.

${ }^{2}$ For a discussion of these cases see Ross (2004b).

${ }^{3}$ This is for example the case of countries like Benin, which has only few natural resources, or of small oil-rich countries like Brunei or Qatar, where natural resources are evenly spread.

${ }^{4}$ Examples for this include Chile and Mongolia.
} 
In a country level empirical analysis, we study how the unevenness of geographical distribution of petrol fields across ethnic groups in a given country affects the likelihood of conflict. For this purpose we have put together a panel of 157 countries with sample period 1960-2008, and have constructed a new variable, Oil Gini, which captures how unevenly oil holdings are spread between different ethnic groups in a country. ${ }^{5}$ To the best of our knowledge we are the first ones to have constructed such a measure of inter-ethnic inequality in abundance of petrol fields. In the regression analysis we include -in addition to our main, new variable of interest- the standard battery of control variables, as well as country fixed effects and annual time dummies. We find that our novel Oil Gini measure has a statistically significant and quantitatively strong positive effect on the likelihood of civil war onsets, as predicted by our theory.

Next, we move to a more disaggregated level of analysis: we study the effect of natural resource unevenness on civil war with a panel dataset at the ethnic group level, covering 1120 ethnic groups and spanning over the period 1960-2006. This has the advantage that unobserved heterogeneity problems are reduced, and ethnic group level data allows us to better discriminate between our theory and competing explanations: our model predicts that conflicts are fuelled by non-governing ethnic minority groups living in very oil rich regions, while alternative mechanisms (discussed below) predict conflict onsets in the presence of oil-rich ethnic groups that control the government. While our country level regressions only establish the link between inter-group oil unevenness and civil war onset, the ethnic group level regressions will be able to distinguish such different mechanisms, and show that it is indeed oil abundance in the regions mostly inhabited by powerless groups, rather than in the homelands of governing ethnic groups, that drives civil wars.

Our main, novel independent variable on the ethnic group level is the surface of an ethnic group's territory covered with petrol (i.e. oil and gas) as a percentage of the country's total surface covered with petrol. To the best of our knowledge we are the first ones to study civil conflict using an ethnic group panel with natural resource variables that vary for different ethnic groups. We find a statistically significant and quantitatively strong positive effect of the relative resource abundance of a non-governing ethnic group on the likelihood that this group is involved in a civil war onset. We also find that the interaction terms of an ethnic group's relative resource abundance with its group concentration are positive, very sizeable and statistically significant, which is in line with our theoretical predictions. The results are robust for very demanding specifications that control for

\footnotetext{
${ }^{5}$ As discussed in detail in section 3.1.1, we have used the GIS-coordinates of all ethnic groups in the "Georeferencing of ethnic groups" (GREG) dataset (Weidmann, Rod and Cederman, 2010), and have merged them with the geo-referenced petroleum dataset (PETRODATA) from Lujala, Rod and Thieme (2007), which allowed us to construct a time-varying measure of how relatively petrol-rich the homelands of a given ethnic group are. Using this information, we have been able to apply the Gini formula to capture geographical oil unevenness.
} 
ethnic group fixed effects, annual time dummies, time-varying ethnic group level controls and all country-level control variables used in the country-regressions. These findings point out that indeed civil war is likely when resource discoveries happen in regions that are significantly populated by groups that do not belong to the governing coalition in the country.

\section{Related literature}

Natural resources and ethnic divisions are known to be correlated with civil conflict in one way or another (see e.g., Le Billon 2001, Collier and Hoeffler 2004, Ross 2004, Montalvo and ReynalQuerol 2005, Fearon 2005, Lujala, Gleditsch and Gilmore 2005, Humphreys 2005, Lujala 2010, Dube and Vargas 2013), but the theoretical literature does not shed sufficient light yet on the independent and joint causal role of resource concentration and ethnic divisions. The existing theoretical studies about the effect of natural resources on conflict, by and large do not relate to geographic concentration: Caselli and Coleman (2013) focus on the decision of the dominant ethnic group to exploit or not the other groups in terms of the proceeds from extraction of natural resources, but do not take into account how the geographic distribution and the economic features of natural resources affect the risk of ethnic conflict of different kinds; Reuveny and Maxwell (2001) and Grossman and Mendoza (2003) use a dynamic framework to predict that present resource scarcity and future resource abundance cause appropriative competition; Hodler (2006) finds that natural resources lead to more conflicts in fractionalized countries; Rohner, Thoenig and Zilibotti (2013) predict natural resources to have a particularly detrimental effect if initial trust in a country is low; Fearon (2005) argues that natural resources can foster conflict by weakening state capacity; Besley and Persson (2011) and Bell and Wolford (2014) emphasize that weak institutions, low income and large natural resources lead to a greater risk of civil war; van der Ploeg and Rohner (2012) study the two-way interaction between natural resource extraction and civil war, focusing on depletion speed. To repeat, none of these papers consider geographic concentration of resources and how it overlaps with the geographic concentration of minority groups.

Horowitz (1985) did make the anecdotal observation that backward concentrated minorities with resource concentration may have the highest benefit-cost ratio from rebellion, and Walter (2006b) proposed a reputation building theory for why governments tend to repress rebellions in areas with high value of land. However, Walter's reputation theory predicts that the group secession attempts that tend to be blocked are in countries where other groups could otherwise make similar attempts for other resources in other areas. Thus, the explanatory variables with that type of theory would be the number of other relevant groups in the country and the general value of land, more than 
the value of land in that given group's homelands specifically. Neither Horowitz nor Walter allow for frictionless bargaining, whereas, by doing so, we can show that the cases with natural resources concentrated in the homelands of ethnic minorities are exactly those where bargaining can break down, even without any reputation building factor.

The value of mineral resources is a stream of expected future rents. Hence the most important rationalist explanations of war to consider as alternative to ours are those that relate to commitment problems. ${ }^{6}$ It is difficult to commit to any sharing rule if there is an expectation of resource-based changes in the future balance of power, intended both as balance of strength and as balance of control of natural resources that we alluded to above. The fact that commitment problems can lead to preventive war incentives is well established in the literature (see e.g. Levy, 1987, Powell, 1996 and 2006, and the early work of Taylor, 1954). However, the preventive war incentive analysis does not separate or highlight the role of geography or concentration of resources: a minority group could have preventive war incentives to rebel wherever the future enrichment and strengthening of the majority group is expected to come from. Perhaps for this reason, the most recent works on civil war rationalization and natural resources that emphasize commitment problems, like Besley and Persson (2011), Lei and Michaels (2011), and Bell and Wolford (2014), focus on the effects of changes in total amounts or values of resources rather than on distribution and concentration variables. ${ }^{7}$

While the effect of the total quantity and/or value of oil on conflict is ambiguous, ${ }^{8}$ we are able to demonstrate that the unevenness of oil has a robust effect. The shadow of the future argument (related to the fear that an oil discovery could strengthen the government) is equally strong when the oil discovery is in the region controlled by the government; hence the fact that we find a strong and robust impact of the concentration of resources only in the regions mostly populated by minority groups speaks in favor of the type of war motivations that we uncover.

Our paper can also be usefully contrasted with the literature in international relations. There is a common view that preemptive as well as preventive war motivations relate to fear, and not to greed. ${ }^{9}$ In our view, preemptive and preventive wars are much more likely if fear goes hand in hand

\footnotetext{
${ }^{6}$ Asymmetric information and indivisibility, two other popular rationalist explanations of war, do not seem to be particularly relevant in the presence of significant natural resources to be extracted in the future. See Fearon (1995) and Jackson and Morelli (2011) for comparative discussions of the various rationalist explanations of war.

${ }^{7}$ Caselli, Morelli and Rohner (2013) find that geography, and in particular location of borders and resources, matter a lot also for interstate wars. In that interstate war context it is more difficult to disentangle the geographic factors from the commitment problem related incentives.

${ }^{8}$ Cotet and Tsui (2013) find that there is no robust effect of oil reserves on civil wars when controlling for country fixed effects. In contrast, Lei and Michaels (2011) find that oil discoveries lead to more civil wars, perhaps consistently with preventive war motivations.

9 "... the spiral model contends that even a state interested in protecting the status quo can go to war (out of fear), whereas the deterrence model posits that there are status quo states and revisionist states and that only the latter are attackers." (Reiter, 1995: 8). There is a large literature in international relations on this: See e.g. Schelling
} 
with greed: in Esteban, Morelli and Rohner (2012) the decision by a minority group to start a war is preventive, and certainly due to fear of mass killings, but this fear comes up precisely because the group in power is made more greedy (or is afraid that the minority group will become more greedy in the future) due to larger amounts of resources. In this paper, preemptive incentives can be seen in the possibility of an attack due to the fear of being otherwise involved in a less advantageous type of conflict, but once again this fear would not materialize without the complementary greed on one side or the other. Moreover, given the existence of multiple conflict technologies that we emphasize, spirals of events or spiral of beliefs are not necessary for the existence of preemptive war motivations. ${ }^{10}$

In terms of relationship with other empirical studies on civil war, our findings are broadly consistent with the empirical results of Walter (2006a) on the importance of group concentration; Reynal-Querol (2002), Saideman et al. (2002), and Cederman and Girardin (2007) on the importance of ethnic discrimination; ${ }^{11}$ Gates (2002) and Buhaug, Gates and Lujala (2009) on the importance of situations where the rebelling minority group is concentrated in remote peripheral areas, where its odds of winning a local war are larger and conflict tends to be harder to avoid. As far as the empirical literature on inequality and civil conflict is concerned (see e.g. Gurr (2000), Alesina, Michalopoulos, and Papaioannou (2012) and Huber and Mayoral (2013)), our contribution is to show that between-group inequality can be expected to fuel civil conflict if such inequality is mostly in terms of control or shares of resource extraction rents, and especially when resource concentration is interacted with group concentration.

The econometric specification that we use in the analysis at the country level is related to that in Fearon and Laitin (2003), Collier and Hoeffler (2004), Montalvo and Reynal-Querol (2005), Cederman and Girardin (2007), Collier and Rohner (2008), and Esteban, Mayoral and Ray (2012).

The paper is organized as follows: in section 2 we present our theory of bargaining failure and the corresponding predictions; section 3 displays the country level analysis first, followed by the ethnic group level analysis. Section 4 offers some brief concluding remarks. As usual, the proof of the theoretical predictions and the description of the data are relegated to the appendix.

(1966), Jervis (1978), and all the subsequent literature on the security dilemma and spiral of fear.

${ }^{10}$ The offense defense balance theory did already allow for the possibility that preemptive wars can occur due to technology, but in that case they talk about countries having advantages in offense technology over defense technology (see e.g. Snyder, 1984), while we focus on different technological distinctions, more related to geography and motivations.

${ }^{11}$ In their qualitative comparative analysis of oil-exporters Basedau and Richter (2011) find that conflict is more frequent in countries where there are groups from oil-producing regions that are excluded from power. 


\section{$2 \quad$ Model}

\subsection{Setup}

Consider a country populated by two ethnic groups, $i$ and $j .{ }^{12}$ The country is divided in two clearly defined regions, 1,2. We allow for different values of extractable natural resources in regions 1 and 2, labeled $R_{1}$ and $R_{2}$, respectively. ${ }^{13}$ For simplicity, natural resource extraction and export of such resources is the only activity in the country, and this sole activity is conducted by a unique State firm. The group in power can control the sharing of the ensuing surplus. ${ }^{14}$

There are $N_{i}^{1}$ and $N_{i}^{2}$ members of group $i$ in regions 1 and 2 respectively, and $N_{j}^{1}, N_{j}^{2}$ of group $j$. Assume that the two groups are to some degree concentrated in the two regions, group $i$ in region 1 and group $j$ in region $2, N_{i}^{1} / N_{j}^{1}>N_{i}^{2} / N_{j}^{2}$.

We assume that group $j$ controls the government at the beginning of the game, which may mean that group $j$ is a majority group $\left(N_{j}=N_{j}^{1}+N_{j}^{2}>N_{i}=N_{i}^{1}+N_{i}^{2}\right)$ in a democracy, or simply that $j$ had won some conflict for power in a prior period. Group $j$ in power can choose the shares $\alpha,(1-\alpha)$ of the surplus to be attributed respectively to group $i$ and $j$.

There are three potential outcomes: peace $(P)$, secessionist conflict $(S)$, and all-out conflict $(C) .{ }^{15}$ Secessionist conflict refers to war started by the powerless group with the aim of founding an independent State in region 1, while all-out conflict is a conflict where at least one of the two groups aims to fully subjugate the other group in the country. ${ }^{16}$

The time line is as follows:

1. Group $j$ selects $\alpha$;

2. Both groups select non-cooperatively whether they want to initiate a conflict of their choice. In particular, the powerless group can engage in rebellion to initiate all-out conflict $(c)$, it can initiate secessionist conflict $(s)$ or it can remain peaceful $(p)$. The group in power can either engage in repression aiming to capture all rents in all-out conflict $(c)$ or remain peaceful

\footnotetext{
${ }^{12}$ We call the two groups "ethnic groups" only because we need to focus on societies where the population is divided along some identifiable cleavage, but that cleavage could be religion or anything else. Hence we will never require any particular specific component of the concept of ethnicity in our theory.

${ }^{13}$ The variables $R_{1}$ and $R_{2}$ capture the total value of rents, corresponding to the product of the amounts extracted times their price. Hence, $R_{1}$ and $R_{2}$ increase when there are resource discoveries in the two regions (or when the world demand for the potentially different natural resources increases).

${ }^{14}$ Future work could include explicit consideration of the interaction between a government, the minority groups and the extraction companies, rather than assuming State control. For a motivating case study for this future extension, see Morelli and Pischedda (2014).

${ }^{15}$ It is easy to allow also for accepted secession, which however does not add much to the analysis and does not change any of the key results.

${ }^{16}$ An all-out conflict initiated by the group in power could have repression motives, while it takes the form of a rebellion when initiated by the group out of power.
} 
$(p) .{ }^{17}$ As displayed in the matrix below, there is peace $(P)$ when nobody attempts to start any conflict. If only one group attempts to start a conflict or when both groups choose the same type of conflict, in both cases the type of conflict that emerges is clear. If group $i$ tries to initiate secessionist conflict $(s)$, and the government attempts to escalate the conflict into all-out repression $(c)$, this latter attempt succeeds with probability $\theta$ (we will give an extensive interpretation of this parameter in section 2.3 below).

\begin{tabular}{|c|c|c|c|}
\hline & $i$ chooses $p$ & $i$ chooses $c$ & $i$ chooses $s$ \\
\hline$j$ chooses $p$ & $P$ & $C$ & $S$ \\
\hline$j$ chooses $c$ & $C$ & $C$ & $C$ with prob $\theta ; S$ with prob $1-\theta$ \\
\hline
\end{tabular}

\subsection{Payoffs}

If $P$ prevails, total group payoffs from natural resources are

$$
\begin{aligned}
& \pi_{P}^{i}=\alpha\left(R_{1}+R_{2}\right) \\
& \pi_{P}^{j}=(1-\alpha)\left(R_{1}+R_{2}\right)
\end{aligned}
$$

If $C$ is initiated, we assume that the winner takes all the relevant natural resource rents. Thus, the payoffs are as follows:

$$
\begin{aligned}
& \pi_{C}^{i}=p_{c}\left(R_{1}+R_{2}\right)-d_{i}(C) \\
& \pi_{C}^{j}=\left(1-p_{c}\right)\left(R_{1}+R_{2}\right)-d_{j}(C)
\end{aligned}
$$

where $p_{c}$ is the winning probability of group $i$ in all-out conflict and $d_{i}, d_{j}$ are the destruction costs expected from this type of conflict. Think of such costs as mainly capital or infrastructure destruction costs, while adding human life costs, although reasonable even in the mind of leaders, would complicate the algebra without altering the qualitative results of the paper. ${ }^{18}$

The logic of secessionist conflict is similar. We assume that when a group $i$ 's secession attempt is unsuccessful, $i$ is deprived of all resource rents (again, we could allow for further punishment without affecting the qualitative results). When secession is successful, region 1 splits from region

\footnotetext{
${ }^{17}$ For simplicity, we ignore the (unrealistic) possibility that a group in power proposes secession of some region. We could easily extend the framework to allow for it.

${ }^{18}$ In a complementary paper, Esteban, Morelli and Rohner (2012) deal explicitly with the strategic incentives to decimate the population of enemies.
} 
2, and group $i$ gains control over all resources in region 1 . The minorities in the new countries, $N_{j}^{1}$ and $N_{i}^{2}$, are discriminated and do not receive anything after secession. The group leaders have a utilitarian social welfare function with equal weight for any group member. Therefore, the payoffs under secessionist conflict are:

$$
\begin{aligned}
\pi_{S}^{i} & =p_{s} R_{1}-d_{i}(S) \\
\pi_{S}^{j} & =\left(1-p_{s}\right)\left(R_{1}+R_{2}\right)+p_{s} R_{2}-d_{j}(S)
\end{aligned}
$$

where $p_{s}$ is the probability of winning for group $i$ in secessionist conflict.

With this description of the payoffs, the description of the game is complete. After the interpretation of the main assumptions (in section 2.3) and some preliminary observations (in section 2.4) below, we will turn to the equilibrium analysis, using as solution concept the standard Subgame Perfect Equilibrium (SPE).

\subsection{Interpretation of the $\theta$ assumption}

One important assumption in our model is that when group $i$ wants secessionist conflict and group $j$ wants all-out conflict, with probability $(1-\theta)$ the former prevails, and with probability $\theta$ the latter materializes. We now need to motivate this assumption about the uncertainty of conflict type.

As discussed above, secessionist conflict generally entails - when it is feasible- a higher winning chance for group $i$, i.e. $p_{s}>p_{c}$. In fact, when fighting a secessionist conflict, a separatist group can use a "technology of rebellion" (see Kalyvas and Balcells, 2010) and guerrilla tactics - i.e., exploiting its knowledge of the local terrain and population, it can use promising hide-and-ambush tactics - to avoid open-battlefield fighting against the usually stronger government troops (see e.g. Gates (2002) and Buhaug, Gates and Lujala (2009)). In the literature, these privileged guerrilla tactics of ethnic rebels aiming to gain control of the resource rents in their homelands have been called "irregular rebellion or insurgency" by Kalyvas and Balcells (2010), and "sons of the soil" or "peripheral" insurgency by Fearon (2004).

Such guerrilla tactics however require several pre-requisites for being feasible. The condicio sine qua non is that the secessionist group is able to avoid the open battlefield and to hide-and-ambush instead. Besides geographical characteristics such as "rough terrain" (see e.g. Fearon and Laitin, 2003), according to Kalyvas and Balcells (2010: 420) also "material support, revolutionary beliefs and military doctrine", and in particular international military support from major powers, are crucial for sustaining guerrilla insurgency. Also Fearon (2004) emphasizes that "sons of the soil 
insurgencies" need funding to sustain their guerrilla fighting, whereby contraband and cross-border smuggling play important roles.

When the conditions for guerrilla insurgency are not fulfilled, secessionist groups are obliged to fight on the open battlefield like in all-out conflicts. When the "conventional rebellion" technology (with standing armies confronting each other) is the only one available, a secessionist attempt has the same probability of success as any other all-out conflict with any other motivation. Thus, in such cases the rebellion may well become a centrist conflict. ${ }^{19}$.

Some of the factors that can make secessionist guerrilla fighting (with $p_{s}>p_{c}$ ) feasible are subject to exogenous and unanticipated shocks. In particular, the following factors are salient:

First, international support from major powers matters. When the public opinion in Western democracies identifies with a politically excluded ethnic minority, separatist efforts may attract more financial and logistical support from abroad than all-out rebellion, as the former may be seen as act of legitimate defense, while the latter may be interpreted as aggression. This may help to make secessionist conflict feasible, but the reaction of the international community and public opinion is hard to anticipate, and hence constitutes (at least partially) a random shock.

Second, the political situation in neighboring countries can play an important role. Saleyhan (2007) shows systematic cross country evidence that weak neighbors, rival neighbors and refugee diasporas favor rebels' external bases in neighboring countries, and make their guerrilla war efforts more feasible. This is in line with the evidence from recent papers using micro-data and studying how guerrilla insurgences benefit from porous borders (which for example favor the financing of guerilla insurgency through contraband), including Rohner, Thoenig and Zilibotti (2013) for the Ugandan LRA, and Martinez (2013) for the Colombian FARC. Given that domestic politics of neighboring states are time-varying and hard to anticipate, they constitute shocks that make the feasibility of secessionist guerrilla warfare ex-ante a random event.

Third, climate and rain fall shocks make attacks more or less possible. Heavy rain in separatist areas would make it for example harder for the government to move in troops and access the rebels' hiding grounds to force them into the open battlefield. For example, Rogall (2013) shows that in the Rwandan mass killings heavy rain was a major factor to curb assaults from the dominant Hutu troops on peripheral Tutsi communities. Also Koenig et al. (2014) and Vanden Eynde (2011) find that heavy rain could prevent major attacks and battles in the DRC and India, respectively. By its very nature, future climate variation is very difficult to anticipate, which implies that ex-ante the feasibility of secessionist conflict has a random element.

\footnotetext{
${ }^{19}$ Any leader of a rebel group would prefer winning $\left(R_{1}+R_{2}\right)$ with probability $p_{c}$ rather than winning only $R_{1}$ with probability $p_{c}$.
} 
Fourth, a further pre-condition for launching successfully a secessionist guerrilla insurgency is the support from the local population. This also depends on factors with random variation that is hard to know ex-ante, such as for example the charisma of local rebel commanders, or the outside options of the local population -which depends on the harvest (see Miguel, Satyanath and Sergenti, 2004).

Fifth, some types of arms are better suited for all-out battlefield fighting, while others are particularly well-suited for guerrilla tactics such as hide and ambush. The availability and price of different weapon types depends on various continental and international factors that vary a lot over time and are hard to anticipate (see e.g. Killicoat, 2007).

For all these reasons, the groups in conflict can be reasonably described as knowing only the ex-ante probability $(1-\theta)$ that the secessionist guerrilla technology will be available, but not the realization of the exogenous draw of all those sources of uncertainty.

\subsection{Preliminary observations}

In a perfect and frictionless world, war could never occur, as it is a costly lottery, and the destruction cost of war implies that there should exist mutually beneficial Pareto improvements through bargaining. Having allowed group $j$ to choose $\alpha$ at the beginning of the game is equivalent to assuming that bargaining frictions like commitment problems do not apply to this setting. Given that we have also complete information and full divisibility, none of the standard rationalist explanations of war (Fearon, 1995) applies. Nor there is any agency friction, like in Jackson and Morelli (2007). The intuition for why war may occur in our model, in spite of the absence of standard frictions in the choice of $\alpha$, is as follows: while the possibility of bargaining with transfers eliminates war when there is only one disagreement point or threat point, the fact that there exist two types of war and the possibility that the probability of winning for group $i$ may differ significantly between the two types of war creates a bargaining game with two threat points, where each one can be triggered by the first mover. Therefore, even if in expectation peace dominates war given the endogenous $\alpha$ and the exogenous $\theta$, what matters is the unilateral incentive to deviate and trigger the preferred war if the opponent stays peaceful. These unilateral deviation incentives become unavoidable, as we see below, when resources abound in the region inhabited particularly by the minority group. Hence, the geography of natural resources, which is the focal point of the paper, is ultimately the decisive factor driving war and peace in our framework.

Another important note concerns the role of wealth. In the model the variables $R_{1}, R_{2}$ play the role of "prizes", hence they represent the present discounted value of the future stream of rents 
that can be derived from extraction, production and export. Obviously we could incorporate in the model also the accumulated past wealth, but we decided to leave that out of the utility functions because after all the main channel through which accumulated past wealth can affect utility is through its impact on the probability of winning and on the destruction costs, which are already included (in abstract reduced form). ${ }^{20}$ Typically only a small fraction of natural resources to be extracted in the future can be damaged by a war, while much of the accumulated physical capital is often destroyed, partly because it is a vital input of the capacity of a fighting group or State in a conflict. Oil fields and diamond mines (and especially their future productivity) "survive" fighting, while high-tech industries and banking suffer considerably from political instability. A similar argument could be applied to distinguish between various sorts of natural resources, according to their risk of destruction in civil war.

\subsection{Analysis and equilibrium wars}

Here we present the main results, relegating all proofs and derivations to Appendix A. On the basis of the expected outcomes for each group in all subgames for any $\alpha$, group $j$ selects the preferred level of $\alpha$ at the beginning of the game, a sort of take it or leave it bargaining. Our main result will be that there are situations in which there exists no value of $\alpha$ that can possibly avoid war, of one kind or the other. ${ }^{21}$

The intuition for the result is as follows. Group $j$ prefers peace to all-out conflict when $\alpha$ is less than or equal to some threshold $\bar{\alpha}$, while group $i$ prefers peace over an attempt to secede for values of $\alpha$ greater than a threshold $\underline{\alpha}_{s}$, which is not necessarily lower than $\bar{\alpha}$ because the two types of conflict have different costs and different probabilities of winning for the two groups. For the range of parameter values such that $\underline{\alpha}_{s}>\bar{\alpha}$ no level of $\alpha$ can be found for which there exists an equilibrium in which civil war can always be avoided. Our bargaining failure result can be summarized in the following proposition:

Proposition 1 There exist parameter values under which no surplus sharing can be found for which there exists an equilibrium in which civil war can always be avoided.

The space of parameters inducing war increases with the geographical concentration of natural resources in the region with relatively fewer members of the ruling group.

\footnotetext{
${ }^{20}$ Note that the qualitative predictions would be unchanged if part of the natural resources were to be destroyed in fighting. Further, the qualitative predictions would also be robust to assuming a part of past wealth to be appropriable in contest.

${ }^{21}$ Note that it wouldn't help to allow $j$ to choose two separate sharing rules, $\alpha_{1}, \alpha_{2}$, for the two regions: in fact, if the parameters are such that no $\alpha$ exists to make peace an equilibrium in the subsequent simultaneous move subgame, then trivially it is not possible to find any peace inducing pair $\alpha_{1}, \alpha_{2}$, since if this were possible then there would exist $\alpha^{\prime}$ such that $\alpha^{\prime}\left(R_{1}+R_{2}\right)=\alpha_{1} R_{1}+\alpha_{2} R_{2}$ that would work, a contradiction.
} 


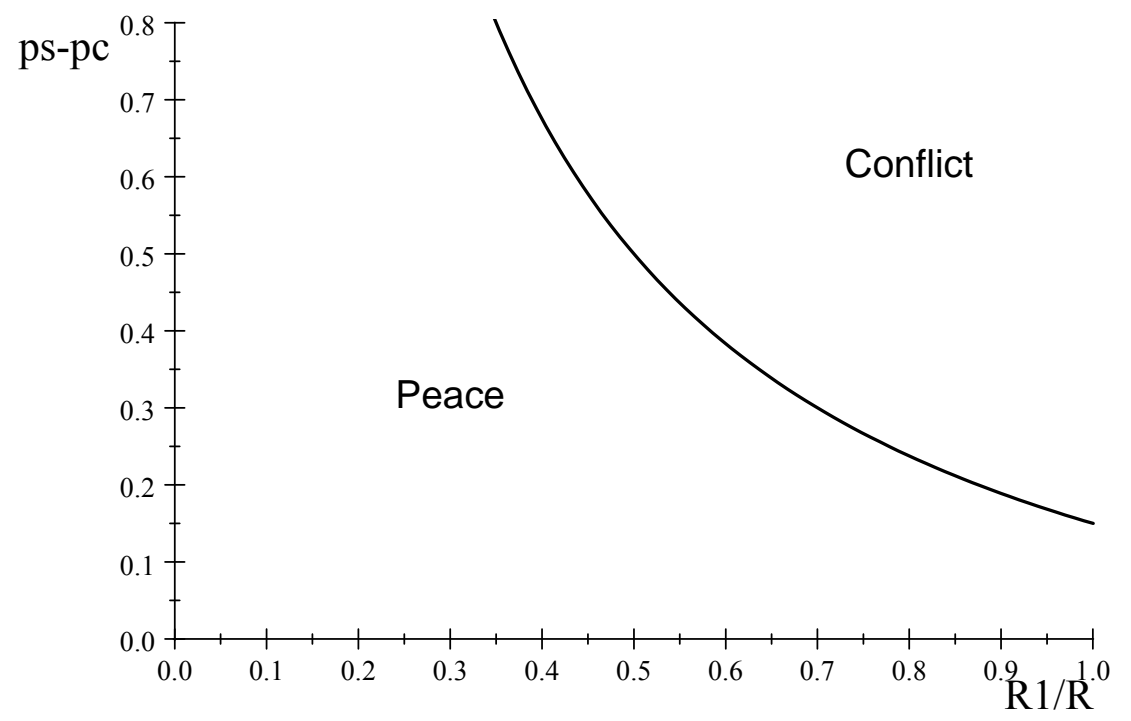

Figure 1: Zones of parameter values for peace and conflict

As shown in the appendix, $\underline{\alpha}_{s}>\bar{\alpha}$ happens when $p_{s} \frac{R_{1}}{R_{1}+R_{2}}>p_{c}+\frac{d_{i}(S)+d_{j}(C)}{R_{1}+R_{2}}$, which obviously becomes more and more likely the greater is $R_{1} /\left(R_{1}+R_{2}\right) \cdot{ }^{22}$

Note that in this game a conflict equilibrium always exists, which is intuitively due to the fact that it takes two for peace, hence no player can unilaterally move out of conflict by deviating from an equilibrium with conflict. However, when $\underline{\alpha}_{s}<\bar{\alpha}$ there also exists a second, better equilibrium with always peace, while for $\underline{\alpha}_{s}>\bar{\alpha}$ there does not exist an equilibrium featuring peace. Figure $1^{23}$ displays the zones where a peace equilibrium exists (labelled "Peace") and the zone where conflict can never be avoided (labelled "Conflict"). We can see that bargaining failure happens when the share of natural resources that are situated in region $1, R_{1} / R$, is large, and when the group out of power has a substantially larger winning probability in secessionist than in all-out conflict, i.e. when $p_{s}-p_{c}$ is large. Other interesting predictions can be added when unbundling the probabilities of winning in the different types of conflict, which is what we do in the following subsection.

\subsection{Generating empirically testable predictions}

There are two necessary conditions for bargaining failure (i.e. for no peace equilibrium existing): first, natural resources need to be distributed unevenly (i.e. high $R_{1} /\left(R_{1}+R_{2}\right)$ ), and second, the powerless group's winning probability under secessionist war needs to be substantially larger than the winning probability in an all-out conflict (i.e. high $p_{s}-p_{c}$ ). If either of these two conditions

\footnotetext{
${ }^{22}$ Intuitively, when $R_{1} /\left(R_{1}+R_{2}\right)$ or $p_{s}-p_{c}$ are very small, secessionist conflict is not attractive and we would fall back into a situation with only one form of salient threat (i.e., all-out conflict).

${ }^{23}$ The following parameter values have been used in this Figure: $R_{1}+R_{2}=1, p_{c}=0.2, d_{i}(S)=0.05, d_{j}(C)=0.1$.
} 
does not hold, there exists an equilibrium in which bargaining will succeed to prevent conflict.

The first condition on relative natural resource abundance of the homelands of the powerless group does not require further disaggregation to be operationalized for empirical testing. In contrast, the winning chances for the powerless group in secessionist versus all-out war are still a blackbox. We now analyze the main determinants of relative strength, and hence of the probability of winning, leading to more testable implications.

Denoting by $W_{i}$ and $W_{j}$ the accumulated usable wealth by group $i$ and group $j$, the probability with which $i$ wins an all-out conflict can be expressed as:

$$
p_{c}=\frac{N_{i} W_{i}}{N_{i} W_{i}+N_{j} W_{j}+\lambda}
$$

where $\lambda$ measures the extra strength of group $j$ due to the control of the government and perhaps the army. In this contest success function (CSF) the ratio of total wealth matters. Like Jackson and Morelli (2007) and Esteban and Ray (2011) we regard accumulated wealth as capacity, and therefore assume a group's probability of winning to be increasing in its total wealth. Finally, this expression allows for the obvious relevance of population sizes, especially in traditional warfare that is typical of many civil conflicts.

Consistently, group i's winning probability in secessionist conflict can be expressed as follows:

$$
p_{s}=\frac{N_{i}^{1} W_{i}}{N_{i}^{1} W_{i}+N_{j}^{1} W_{j}+\lambda /(1+\phi)}
$$

where the government's advantage of controlling a standing army $(\lambda)$ is discounted by $(1+\phi)$, and $\phi$ is a non-negative parameter that is an increasing function of the geographical distance between the secessionist homelands and the capital. This is in line with the idea that the military power of the government decays when projected at a large distance (see e.g. Boulding, 1962). It is also consistent with the recent literature that has found that geographical remoteness and ideological recruitment provide a larger advantage for group $i$ in secessionist than in all-out wars (see e.g. Gates, 2002; Buhaug, Gates and Lujala, 2009). The parameter $\phi$ also depends on various factors discussed in section 2.3 that affect the scope for hide-and-ambush guerrilla insurgency. Note also that in case of a secessionist conflict the men used are only those in the conflict region. ${ }^{24}$ Using the explicit dependence of $p_{s}$ and $p_{c}$ on the distribution of populations of the different groups in

\footnotetext{
${ }^{24}$ Gates (2002) and Buhaug, Gates and Lujala (2009) find evidence that when the minority group is concentrated the odds of winning are larger.
} 
the territory, the condition for bargaining failure becomes

$$
\frac{N_{i}^{1} W_{i}}{N_{i}^{1} W_{i}+N_{j}^{1} W_{j}+\lambda /(1+\phi)} \frac{R_{1}}{\left(R_{1}+R_{2}\right)}>\frac{N_{i} W_{i}}{N_{i} W_{i}+N_{j} W_{j}+\lambda}+\frac{d_{i}(S)+d_{j}(C)}{R_{1}+R_{2}}
$$

This reveals that for various possible parameter values civil war is on average more likely when the minority group $i$ is very concentrated (large $N_{i}^{1}$ ) and the corresponding region relatively homogeneous (low $N_{j}^{1}$ ); and state capacity is low (i.e., low $\left.\lambda\right)^{25}$. The results of the comparative statics implied by the characterization of Proposition 1 are summarized below.

Corollary 1 Conflict occurs for a larger set of the other parameters when

1. most of the natural resources are located in the region of the powerless group,

2. the winning chances of the group out of power are much better for secessionist than for all-out conflict,

3. war is not very destructive,

4. the powerless group is very concentrated in a relatively homogeneous region,

5. state capacity is low,

6. the region of the group out of power is further away from the capital.

To establish another natural baseline, consider a proportional democratic benchmark, in which surplus sharing is determined by vote strength, i.e., $\alpha^{D}=\frac{N_{i}}{N_{i}+N_{j}}$ and where there is perfect wealth equality, i.e., $W_{i}=W_{j}$. If conflict is not very destructive and if an ethnic group out of power is very concentrated in an area with large resource rents (high $N_{i}^{1}$ and high $R_{1}$ ), even such democracy in an egalitarian society cannot guarantee peace in the best SPE. We can even end up in a situation where any of the two groups would like to start war because $\underline{\alpha}_{s}>\alpha^{D}>\bar{\alpha} .{ }^{26}$ This can occur when the minority group is very concentrated (large $N_{i}^{1} / N_{j}^{1}$ ), when the geographical distribution of natural resources is unequal (high $R_{1} /\left(R_{1}+R_{2}\right)$ ), conflict is not very destructive, and when state capacity is neither too small nor too large (intermediate $\lambda$ ). For these parameter values either group would like to start conflict. If $\alpha^{D}$ is either below $\bar{\alpha}$ or above $\underline{\alpha}_{s}$, but still $\underline{\alpha}_{s}>\bar{\alpha}$, then only one group has interest in starting a conflict, but we cannot determine which conflict will actually

\footnotetext{
${ }^{25}$ Conflict is more likely for low state capacity, as long as $\phi$ (i.e. the parameter capturing among others remoteness of group $i$ 's homelands) is not too large.

${ }^{26}$ Expressed in structural parameters, this corresponds to $\frac{N_{i}^{1} W_{i}}{N_{i}^{1} W_{i}+N_{j}^{1} W_{j}+\lambda /(1+\phi)} \frac{R_{1}}{\left(R_{1}+R_{2}\right)}-\frac{d_{i}(S)}{R_{1}+R_{2}}>\frac{N_{i}}{N_{i}+N_{j}}>$ $\frac{N_{i} W_{i}}{N_{i} W_{i}+N_{j} W_{j}+\lambda}+\frac{d_{j}(C)}{R_{1}+R_{2}}$.
} 
occur, since as soon as at least one group has interest in conflict both groups try to impose their preferred way to fight it.

The relevance of the above considerations about the $\alpha^{D}$ benchmark is that even when the two groups are equally well off from the past and democracy has already been achieved, a new conflict can erupt because of regional new resources, if $R_{1}$ jumps sufficiently high. Note also that if we start from a non democratic surplus sharing regime, for example with an $\alpha$, such that $\alpha<\bar{\alpha}<\alpha^{D}<\underline{\alpha}_{s}$, the most promising policies to establish peace would be related to fostering development rather than pushing democracy, as development would result in larger destruction costs of war, and would thereby make bargaining easier, while democracy would still not secure peace when $\underline{\alpha}_{s}>\alpha^{D}>\bar{\alpha}$.

\subsection{A remark on the comparison with other theories of war}

We want to stress that it would not be easy to obtain our equilibrium prediction about the role of resource concentration and group concentration in a different model that used one of the standard frictions discussed in the rationalist explanations of war by Fearon (1995).

For example, a "preventive" war incentive logic would generate different predictions: if a region like region 1 is expected to become increasingly richer in terms of resources, the expectation of future increase in strength and sharing demands by the minority group associated with that region can increase the temptation by the ruling group to enact some type or another of preventive repression or expropriation; however, while these incentives would be complementary to the logic of our model, the prevalence of preventive war incentives could also work the other way: an increase in $R_{2}$ could determine an expectation of future increase in exploitation power by group $j$ in power, increasing thereby the incentives of group $i$ to rebel in an all-out conflict because of the expected increase in $R_{2}$. Thus, while our model unambiguously predicts that the civil war probability increases with

$\frac{R_{1}}{R_{1}+R_{2}}$, preventive war motivations would not distinguish between increases of $R_{1}$ and $R_{2}$, both potentially leading to greater shadow of the future.

We will now show that our main theoretical predictions find a strong validation in the data.

\section{Empirical Analysis}

The existing empirical literature on natural resources and civil war has two main weaknesses: First, it only studies the effects of the total amount of natural resources and not of their geographical distribution. Second, it studies the impact of natural resource abundance mostly on the country level rather than on the ethnic group level. On such an aggregate level of analysis there is more unobserved heterogeneity in the data, and some of our predictions relate to ethnic group characteristics, 
which calls for a test on this disaggregated level.

To address these concerns, we will now perform our own empirical analysis. First, we will use panel data on the country level and construct our novel oil inequality measure. Based on georeferenced petrol field and ethnic group location data, we are able to compute a Gini Index of how unevenly petrol fields are spread between different ethnic groups in a given country. Using a standard specification of control variables and including country fixed effects, we will demonstrate that petrol unevenness has a positive and significant effect on the likelihood of civil conflict.

Afterwards, we will move to a panel on the ethnic group level. Using a variety of control variables, as well as country fixed effects / ethnic group fixed effects, it will be shown that indeed the ethnic groups out of power who are relatively oil rich with respect to the rest of the country will be significantly more likely to be involved in civil conflict. We also find that the interaction terms between oil abundance and group concentration, resp. distance from capital are positive and significant, pointing out that indeed civil wars are more likely when $R_{1} /\left(R_{1}+R_{2}\right)$ and $p_{s}-p_{c}$ are both large, as predicted by our theory.

\subsection{Empirical Analysis: Country Level}

Our goal in this section is to analyze how the unevenness of geographical distribution of petrol fields across ethnic groups in a given country impacts on the likelihood of conflict. For this purpose we have put together a panel of 157 countries with sample period 1960-2008, and have constructed a novel variable, Oil Gini, which we will describe in more detail below. In our regressions we use -in addition to our main, new variable of interest- the standard battery of control variables, as well as country fixed effects and annual time dummies. Below we start by describing in some detail the data.

\subsubsection{Data and Specification}

Given that our theory focuses on bargaining failure to avoid conflict outbreaks, a natural choice of dependent variable is the onset of civil conflicts. The source of the civil war data is "UCDP/PRIO Armed Conflict Dataset" (UCDP, 2012), which is the most commonly used standard data source for civil wars at the country level ${ }^{27}$. We focus on the widely used standard definition of civil war, counting a country and year as having a civil war when at least 1000 casualties are recorded in a given year. Our conflict onset variable takes a value of 1 when a new civil war starts, is coded as missing during wars (where by definition a war cannot newly start), and is coded as 0 for peace.

\footnotetext{
${ }^{27}$ This dataset has been used, among others, by Besley and Persson (2011) and Esteban, Mayoral and Ray (2012).
} 
In a robustness check we will also show that our results are robust when focusing on war incidence as dependent variable (where ongoing wars are also coded as one). ${ }^{28}$

To construct our main novel "Oil Gini" measure, we started out from the ethnic group level. First, we constructed a panel dataset on the ethnic group and year level using the sample of ethnic groups in the "Geo-referencing of ethnic groups" (GREG) dataset (Weidmann, Rod and Cederman, 2010). ${ }^{29}$ Relying on maps from the classical "Soviet Atlas Narodov Mira" from 1964 (Bruk and Apenchenko, 1964), which is still very extensively used for ethnolinguistic fractionalization (ELF) indices, GREG is a geo-referenced dataset with the coordinates of the group boundaries of 1120 ethnic groups.

One major advantage of this dataset is that it provides a global coverage of ethnic groups for the whole world, containing relatively precise information on the geographical location of groups, which enables us to merge it with other geo-referenced group-level data using Geographical Information Systems (GIS). In contrast, the main alternative datasets on ethnic groups like the "Minorities at Risk" data (Minorities at Risk, 2009), the "Ethnologue" (Lewis, 2009), and the lists of ethnic groups from Alesina et al. (2003), resp. Fearon (2003) lack detailed geographical information on the location of ethnic groups in all countries. ${ }^{30}$

The fact that the GREG data is a non-time varying snapshot from the early 1960s has both advantages and disadvantages. On the negative side, it implies that in some instances the group boundaries are not fully accurate in recent decades, although thankfully group borders generally evolve very slowly over time. The fact that the group border information is not time-varying lowers accuracy and hence adds noise to our estimations, which biases the magnitude of coefficients and the significance levels downwards, while there seems to be no other obvious bias of the results. This means that using GREG will tend to bias the results against us and making them appear less strong than they are in reality.

On the positive side, using ethnic group borders from the beginning of our sample -which hence

\footnotetext{
${ }^{28}$ The war onset variable relates to the question of what makes wars break out, while the war incidence variable is designed to capture the total intensity of conflict, which is not only driven by factors making wars start, but also by factors making wars last.

${ }^{29}$ Throughout the database construction we use the country borders from the time-varying, geo-referenced "CShapes" dataset (Weidmann, Kuse, and Gleditsch, 2010).

${ }^{30}$ Very few other datasets on ethnic groups provide geographical information. The "Ethnographic Atlas" (Gray, 1999) includes one longitude and one latitude for each group, but does not provide polygons of the group territories, which are needed for computing our main new variables. Wucherpfennig et al. (2011) have also put together a dataset on ethnic groups with location information ("Ethnic Power Relations" (EPR)). They, however, do not include all ethnic groups, but only those that have been judged as "politically relevant", which could result in endogenous sample selection if the judgment of group "relevance" is affected by past political outcomes like wars. Controlling for past wars would not address this issue, as the concern is about the potential bias of the composition of the sample itself, with peaceful groups being less likely to be viewed as politically relevant, and hence more likely to be omitted from the sample. If these omitted groups differ in key characteristics from the included groups, the beta coefficients in the regression are biased.
} 
pre-date the conflict observations in our regressions- has the advantage to alleviate concerns of ethnic group locations being endogenous to the wars that we want to explain. Still, there remains the possibility that past wars and existing oil fields had some impact on location patterns of ethnic groups -although such concerns are of course alleviated by the fact that ethnic group homelands are very stable. To address such remaining concerns we control for past conflict in all regressions and we include additional robustness tables in the appendix showing that our results also hold for a restricted sample that includes only observations of countries that did not have oil in 1964 when the "Soviet Atlas Narodov Mira" underlying GREG was put together.

Using GIS-Software (ArcGIS) we have then merged the GREG data with the geo-referenced petroleum dataset (PETRODATA) from Lujala, Rod and Thieme (2007), which documents where oil fields lie. Given that discovery dates of oil fields are available, this allowed us to construct a time-varying map of oil fields. Combining this information with the ethnic group data we were able to compute for every country and year the area occupied by a given ethnic group and also the area occupied by oil fields lying in the ethnic group's territory. Using this information, and the standard formula of the GINI inequality index, we were able to compute a novel, time-varying measure of the unevenness of oil field distribution across ethnic group for a given country and year, which we call the "Oil Gini" variable. ${ }^{31}$

It is important to note the limits of the "Oil Gini" measure. Given that we lack data on the amounts of oil produced by ethnic groups, and only have data on the territory covered by oil, our novel "Oil Gini" variable is not a perfect measure of oil unevenness, but rather an imperfect proxy. However, the statistical noise of this measure does not appear biased in any particular direction. Hence, we expect our results to be conservative estimates suffering from attenuation bias, i.e. which makes our findings to appear weaker that they are in reality.

We use a standard battery of control variables, which results in a specification that is extremely close to the core specifications run by Fearon and Laitin (2003), Collier and Hoeffler (2004), Montalvo and Reynal-Querol (2005), Cederman and Girardin (2007), Collier and Rohner (2008), and Esteban, Mayoral and Ray (2012). Like these papers, we control for natural resource abundance (i.e., an updated version of Fearon and Laitin's (2003) "oil exporter" variable), GDP per capita, democracy, population size, whether a state was recently created, ethnic fractionalization, geography (mountainous terrain and noncontiguous states), and peace duration. In robustness checks we control for alternative war persistence measures (lagged war incidence, the number of war years in the last five year period), and alternative natural resource measures (gold producer, diamond producer, oil production per capita). All these variables are described in more detail in Appendix

\footnotetext{
${ }^{31}$ Note that for countries without oil the "Oil Gini" variable takes a value of 0.
} 
C. To account for omitted variable bias and unobserved heterogeneity we include from column 2 onwards country fixed effects and annual time dummies, and we allow the robust standard errors to be clustered at the country level. We will as default run linear probability models, which have the advantage of providing easily interpretable coefficients and allowing for clustered standard errors in the presence of country fixed effects. We will however show in a robustness check that the results are robust to using conditional logit.

To summarize, we estimate the following main specification (corresponding to column 3 of Table 1):

$$
W a r_{c, t}=\alpha O i l_{-} G i n i_{c, t}+\mathbf{X}_{c, t}^{\prime} \boldsymbol{\beta}+\mathbf{Y}_{c}^{\prime} \boldsymbol{\gamma}+\mathbf{Z}_{t}^{\prime} \boldsymbol{\delta}+u_{c, t}
$$

where $\mathbf{X}_{c, t}^{\prime}$ is a vector of time-varying and country-varying control variables, $\mathbf{Y}_{c}^{\prime}$ is a vector of country fixed effects, $\mathbf{Z}_{t}^{\prime}$ is a vector of annual time dummies, and $u_{c, t}$ is the error term. The coefficient of interest is $\alpha$, which our theory predicts to be of positive sign.

\subsubsection{Results}

In Table 1 we display the results of the country level regressions. In the first column we run a linear probability model with just the battery of standard controls, but without our new "Oil Gini" measure. For comparability with most papers in the existing literature (e.g. the classic article of Fearon and Laitin, 2003) we focus on a specification without country and time fixed effects, where standard errors are left unclustered. Besides the "New State" variable, all other variables have the expected sign. In line with the existing literature (see e.g. Fearon and Laitin (2003), Collier and Hoeffler (2004), Montalvo and Reynal-Querol (2005), Cederman and Girardin (2007), Collier and Rohner (2008), and Esteban, Mayoral and Ray (2012)), we find that oil abundant, ethnically fractionalized and very populated states with low GDP per capita and a track record of past violence are more likely to experience civil war onsets.

In column 2 we add country fixed effects and annual time dummies, and allow for robust standard errors to be clustered at the country level, in the goal of addressing omitted variable bias and unobserved heterogeneity. As noted in the literature (Fearon and Laitin, 2003; Collier and Hoeffler, 2004; Sambanis, 2004; Collier, Hoeffler and Rohner, 2009) adding country fixed effects tends to remove the significance of most variables in such civil war regressions. In column 3 we now add our new "Oil Gini" measure, which has the expected sign and is significant at the 10\% level. Its effect is quantitatively important: Moving a country from full ethnic oil equality to full oil inequality increases the war risk by 6.6 percentage points, which is more than four-fold the baseline 


\begin{tabular}{|c|c|c|c|c|c|c|}
\hline & \multicolumn{6}{|c|}{ Dependent variable: Civil War Onsets } \\
\hline & (1) & $(2)$ & (3) & $(4)$ & (5) & (6) \\
\hline \multirow[t]{2}{*}{ Oil Gini } & & & $0.066^{*}$ & $7.955^{* *}$ & $0.098 * *$ & $0.065^{*}$ \\
\hline & & & $(0.035)$ & (3.912) & $(0.045)$ & $(0.035)$ \\
\hline \multirow[t]{2}{*}{ Oil exporter (t-1) } & $0.016 * *$ & 0.018 & 0.021 & $2.774^{* *}$ & 0.014 & 0.019 \\
\hline & $(0.007)$ & $(0.017)$ & $(0.019)$ & $(1.258)$ & $(0.014)$ & $(0.016)$ \\
\hline \multirow[t]{2}{*}{ In GDP p.c.(t-1) } & $-0.004 *$ & -0.009 & -0.006 & -0.363 & 0.001 & -0.006 \\
\hline & $(0.002)$ & $(0.008)$ & $(0.009)$ & $(0.589)$ & $(0.014)$ & $(0.009)$ \\
\hline \multirow[t]{2}{*}{ Democ. $(t-1)$} & 0.000 & $-0.001 *$ & $-0.001 *$ & -0.040 & -0.000 & $-0.001 *$ \\
\hline & $(0.000)$ & $(0.000)$ & $(0.001)$ & $(0.042)$ & $(0.001)$ & $(0.001)$ \\
\hline \multirow{2}{*}{ In Popul.(t-1) } & $0.004 * * *$ & 0.005 & 0.006 & -2.449 & 0.011 & 0.006 \\
\hline & $(0.001)$ & $(0.010)$ & $(0.011)$ & $(1.974)$ & $(0.014)$ & $(0.011)$ \\
\hline \multirow[t]{2}{*}{ New State } & $-0.014 * * *$ & 0.007 & 0.008 & 1.799 & 0.009 & 0.009 \\
\hline & $(0.004)$ & $(0.006)$ & $(0.006)$ & $(1.273)$ & $(0.008)$ & $(0.006)$ \\
\hline \multirow[t]{2}{*}{ Ethnic Fraction. } & $0.014 * *$ & & & & & \\
\hline & $(0.007)$ & & & & & \\
\hline \multirow[t]{2}{*}{ Mountainous Terr. } & 0.003 & & & & & \\
\hline & $(0.008)$ & & & & & \\
\hline \multirow[t]{2}{*}{ Noncontig. State } & 0.006 & & & & & \\
\hline & $(0.005)$ & & & & & \\
\hline \multirow[t]{2}{*}{ Peace duration } & $-0.001 * * *$ & -0.000 & -0.000 & $0.025^{*}$ & & -0.000 \\
\hline & $(0.000)$ & $(0.000)$ & $(0.000)$ & $(0.014)$ & & $(0.000)$ \\
\hline \multirow[t]{2}{*}{ Civ. War Incid. (t-1) } & & & & & $0.575^{* * *}$ & \\
\hline & & & & & $(0.040)$ & \\
\hline \multirow[t]{2}{*}{ Oil Exp. * Oil Gini } & & & & & & 0.004 \\
\hline & & & & & & $(0.042)$ \\
\hline Model & OLS & OLS & OLS & Logit & OLS & OLS \\
\hline Country Fixed Eff. & No & Yes & Yes & Yes & Yes & Yes \\
\hline Observations & 5289 & 5417 & 5180 & 1093 & 5421 & 5180 \\
\hline R-squared & 0.024 & 0.105 & 0.112 & 0.227 & 0.544 & 0.112 \\
\hline \multicolumn{7}{|c|}{$\begin{array}{l}\text { Notes: Dependent variable: Civil war onset (unless in column } 5 \text { where the dependent variable is Conflict } \\
\text { incidence). The dependent variable is coded as } 1 \text { if a conflict causing at least } 1000 \text { fatalities is starting in a } \\
\text { given year. Sample period: } 1960-2008 \text {. Number of countries for which observations are available: } 157 \text {. } \\
\text { From column } 2 \text { onwards unreported country fixed effects and annual time dummies are included, and } \\
\text { robust standard errors are allowed to be clustered at the country level (unless in the conditional logit } \\
\text { regression of column } 4 \text { where clustering of standard errors is not possible). Significance levels: }{ }^{*} p<0.1,{ }^{* *} \\
\text { p<0.05, }{ }^{* * *} p<0.01 \text {. }\end{array}$} \\
\hline
\end{tabular}

Table 1: Country Level Regressions of the Effect of Oil Gini on Conflict Onsets 
risk of 1.5 percentage points.

In columns 4 and 5 it is shown that the effect of Oil Gini is robust to running logit regressions instead of OLS and to having "civil war incidence" rather than "civil war onset" as dependent variable: In both columns, Oil Gini has a positive sign and is significant at the 5 percent level.

In column 6 we also include an interaction term of Oil Gini and our dummy variable taking a value of 1 for big oil exporting countries. The coefficient of Oil Gini remains positive and significant, while the interaction term also has the expected positive sign, but is not statistically significant.

In Table 3 in Appendix B we provide some additional results. First, columns 1-3 show that Oil Gini continues to be statistically significant and to have a coefficient of similar magnitude when we control for an alternative war persistence variable and for other natural resource measures (gold producer, diamond producer and oil production per capita). In columns 4-6 we re-run the main regressions of columns 3, 5 and 6 of Table 1, but restricting the sample to observations from countries that did not have oil in 1964 when the "Atlas Narodov Mira" (Bruk and Apenchenko, 1964) -which is the primary source for our geo-referenced ethnic group location dataset- was put together. This restriction of the sample serves the purpose of alleviating concerns that oil abundance could have affected the location of ethnic groups.

Even in these very demanding regressions run on a restricted sample our main Oil Gini variable has the expected sign and is statistically significant. Interestingly, also the interaction term of Oil Gini with Oil Exporter in column 6 is of the expected positive sign and statistically significant.

\subsection{Empirical Analysis: Ethnic Group Level}

To test the predictions of our theory on the impact of the relative oil richness of the ethnic groups on civil war onsets, we have put together a panel dataset on the ethnic group level, covering 1120 ethnic groups and spanning over the period 1960-2006. In particular, we include all ethnic groups of the "Geo-referencing of ethnic groups" (GREG) dataset (Weidmann, Rod and Cederman, 2010), and construct group level variables that capture closely the expression $R_{1} /\left(R_{1}+R_{2}\right)$ of the model, as explained above. There is a small number of papers in the literature that study civil war on the ethnic group level (e.g., Walter, 2006; Cederman, Buhaug and Rod, 2009), but these papers typically either ignore natural resources or use a natural resource abundance variable at the countrylevel, which does not allow to capture unevenness of natural resource distribution. ${ }^{32}$ Hence, to the best of our knowledge we are the first ones to study civil war using a panel on the ethnic group

\footnotetext{
${ }^{32}$ Esteban, Morelli and Rohner (2012) use an ethnic-group level resource abundance measure to study massacres of civilians, but they do not include in their analysis any variable of a group's relative natural resource abundance with respect to the other groups in the country.
} 
level with natural resource variables that vary for different ethnic groups.

Looking at this disaggregated level of analysis has several advantages: With more fine grained data typically unobserved heterogeneity and omitted variable problems are reduced. Further, studying group level data also allows us to better discriminate between our mechanism and other mechanisms. Our theory predicts that conflicts become more likely to break out if a powerless ethnic minority group becomes very oil rich. Alternative theories could predict conflicts to break out when the governing ethnic group becomes more oil rich. So far, our country level regressions only established the link between oil unevenness between ethnic groups and civil war onsets. However, the country level analysis was not able to distinguish between our theory and alternative theories stressing for example war triggered by oil rich governing groups. In contrast, the current ethnic group level regressions will be able to distinguish such different mechanisms, and will be able to conclude whether the dangerous type of oil unevenness is indeed when powerless groups are oil abundant, as predicted by our theory.

\subsubsection{Data and Specification}

The main dependent variable is civil war onset at the group level and is taken from Cederman, Buhaug and Rod (2009). It varies on the ethnic group and year level and takes a value of 1 when in a given year a civil war newly starts that involves a given ethnic group. It is coded as missing for ongoing wars, and as 0 if the ethnic group is not involved in a civil war in a given year.

Our main independent variable is the surface of an ethnic group's territory covered with oil and gas as a percentage of the country's total surface covered with oil and gas. This proxies well $R_{1} /\left(R_{1}+R_{2}\right)$. To construct this measure, we used as starting point all ethnic groups in the "Geo-referencing of ethnic groups" (GREG) dataset (Weidmann, Rod and Cederman, 2010), which allowed us to know the geographical coordinates of where a given ethnic group is located. Then we merged this with the geo-referenced petroleum dataset (PETRODATA) from Lujala, Rod and Thieme (2007), which documents where oil fields lie and when they have been discovered. Combining this information we were able to compute a variable measuring which part of the territory occupied by a given ethnic group contains oil. Expressing this in terms of the total surface containing oil in the country, we obtain a quite precise, time-varying measure of how relatively petrol-rich the homelands of a given ethnic group are.

We also include various control variables on the ethnic group level. In particular, we include two time-varying demographic controls, Group Population / Governing Groups' Population and Governing Groups' Population from Cederman, Buhaug and Rod (2009). Note that while the pop- 
ulation estimates of each ethnic group are not time varying, the composition of groups controlling the government is time varying, which makes these measures time-varying. Further, we construct different war persistence measures (Group Peace Duration, and lagged Group War Incidence). In addition, we control for several time-invariant geographical and demographic factors, i.e. Group Diamond Mines (constructed using raw data from Gilmore et al., 2005), Group co-ethnics abroad (constructed based on the GREG dataset), Group's share of mountainous terrain and ln group's distance to capital (from Cederman, Buhaug and Rod, 2009), Group's soil quality (constructed using the Harmonized World Soil Database from Fischer et al., 2008), Group Population Density (constructed using the geo-referenced population density data from the Socioeconomic Data and Applications Center at Columbia University, see Sedac, 2012).

Further, we also include in two columns interaction terms of our main independent variable $R_{1} /\left(R_{1}+R_{2}\right)$ with a group concentration measure constructed using raw data from Alesina and Zhuravskaya (2011), and with a group distance from capital measure (as described above). All these variables are described in more detail in Appendix C.

Finally, we also include -but do not report- all country-level control variables included in the country-level regressions above and annual time dummies. Like in the country-level regressions above we include robust standard errors allowed to be clustered at the country level. As above, we also run as main specifications linear probability models, but show that the results are robust to the use of conditional logit estimators.

To summarize, we estimate the following main specification (corresponding to column 3 of Table 2):

$$
W a r_{e, t}=\alpha\left(R_{1} / R\right)_{e, t}+\mathbf{W}_{e, t}^{\prime} \boldsymbol{\beta}+\mathbf{X}_{c, t}^{\prime} \boldsymbol{\gamma}+\mathbf{Y}_{e}^{\prime} \boldsymbol{\delta}+\mathbf{Z}_{t}^{\prime} \boldsymbol{\zeta}+u_{e, t}
$$

where $\mathbf{W}_{e, t}^{\prime}$ is a vector of time-varying and ethnic group-varying control variables, $\mathbf{X}_{c, t}^{\prime}$ is a vector of time-varying and country-varying control variables, $\mathbf{Y}_{e}^{\prime}$ is a vector of ethnic group fixed effects, $\mathbf{Z}_{t}^{\prime}$ is a vector of annual time dummies, and $u_{e, t}$ is the error term. The coefficient of interest is $\alpha$, which our theory predicts to be of positive sign.

\subsubsection{Results}

The focus of our empirical analysis is to assess whether conflict indeed becomes more likely when the group out of power has an ethnic homeland that is abundant in oil, i.e. when $R_{1} /\left(R_{1}+R_{2}\right)$ is large, as predicted by the theory. Hence, for most of our regressions, namely in the main table 2 and in the first four columns of the Appendix Table 4, we will use the sample of all ethnic groups 
that are out of power, which corresponds to the largest part of all ethnic groups (i.e. on average about $83 \%$ of all ethnic groups are non-governing groups). ${ }^{33}$ As discussed in more detail below, in the columns 5-6 of the Appendix Table 4 we run as a sort of Placebo test the main regressions on a sample of governing groups.

In the first column of table 2 we regress for a pooled panel our main dependent variable, Civil War Onsets, on the main independent variable $R_{1} / R$ (where $R \equiv R_{1}+R_{2}$ ) and on all controls mentioned above. Our main variable $R_{1} / R$ has the expected positive sign and is significant at the $5 \%$ level. The effect is sizeable: If an initially oil-less ethnic group has after a discovery all the country's oil fields on its territory, the risk of being involved in a civil war onset is increased by 2.7 percentage points, which is about 8-times larger than the relatively small baseline risk for a group to be involved in a conflict onset, which is of 0.3 percentage points.

About half of the control variables are significant. Larger ethnic groups and groups occupying valuable soils are more likely to be involved in conflict onsets, while groups with a peaceful past and ethnic groups with co-ethnics in many other countries are less likely to be involved in civil war onsets.

In column 2 we run the same specification, but now including country fixed effects. Our main variable $R_{1} / R$ remains significant, with a coefficient of similar size. In column 3 we now include group fixed effects. This is a very demanding specification, as all time-invariant group characteristics are controlled for by the group fixed effects (which implies that all time-invariant variables drop from the specification) and the results are purely driven by within-group changes of relative resource abundance over time. Even in this very demanding specification our main independent variable $R_{1} / R$ remains statistically significant (the p-value is 0.053 ), with now a somewhat larger coefficient.

In columns 4 and 5 we show that the results of columns 2 and 3 are robust to running conditional logit estimations with country, respectively group fixed effects, instead of the linear probability models used before.

In columns 6 and 7 we run the same regressions like in columns 2 and 3, but with civil war incidence rather than civil war onsets as dependent variable. While our main variable $R_{1} / R$ remains significant in the presence of country fixed effects, it drops below the $10 \%$ significance threshold when group fixed effects are included. This suggest that indeed our theory is better at predicting the break-outs of wars due to bargaining failure rather than war duration, which also depends on additional factors.

Column 8 shows that our main variable $R_{1} / R$ can also explain the presence of separatist move-

\footnotetext{
${ }^{33}$ Concretely, all ethnic groups are included that do not control the government of their country in a given year, i.e. for which the variable "ethnic group in power" (egip) of Cederman, Buhaug and Rod (2009) takes a value of zero.
} 
ments in a given ethnic group. Given that this variable is ethnic group specific, but not time-varying, we are only able to include country fixed effects, but not group fixed effects.

Our theory predicts that not only $R_{1} / R$ will be a main driving factor of bargaining failure to prevent war, but that also the difference between the winning prospects in secessionist versus in all-out wars, $p_{s}-p_{c}$, matters. As shown in Corollary 1 , the wedge between $p_{s}$ and $p_{c}$ is typically larger when a given ethnic group is very concentrated and located far from the capital.

In column 9 we hence interact our main variable of relative resource abundance, $R_{1} / R$, with a measure of group concentration ranging from 0 to 1 , constructed with raw data from Alesina and Zhuravskaya (2011). While this is the most precise available data for our purpose, it only covers a subset of our ethnic groups, leading to a drop in the sample size. It is also a time-invariant variable, meaning that the baseline group concentration variable drops from the specification as we include group fixed effects, and only its interaction with $R_{1} / R$ remains in the specification. We find a quantitatively strong effect of the interaction term that is significant at the $1 \%$ level, and also $R_{1} / R$ and $\left(R_{1} / R\right) *$ Group Concentration are jointly statistically significant at the $1 \%$ level. This highlights that indeed civil conflict outbreaks are most likely when $R_{1} / R$ and $p_{s}-p_{c}$ are both large, as shown in Corollary 1 and displayed graphically in Figure 1.

In column 10 we include the interaction of our $R_{1} / R$ variable with a dummy of above-median distance from the capital. In line with Corollary 1 we again expect this interaction term to be positive. Indeed, we find a quantitatively large, positive coefficient of this interaction term that is statistically significant at the $1 \%$ level. The variables $R_{1} / R$ and $\left(R_{1} / R\right)^{*}$ Distance from capital are jointly significant at the $5 \%$ level. These findings are consistent with our theory's prediction that indeed civil conflict outbreaks are most likely when $R_{1} / R$ and $p_{s}-p_{c}$ are both large.

The Appendix Table 4 provides additional results. In order to alleviate concerns of oil abundance affecting ethnic group location, we restrict in columns 1-4 like in some country level regressions the sample to groups from countries that did not have oil in 1964, which is the year when our primary ethnic group location data was put together. Column 1 replicates the main regression of column 3 of Table 2 for this restricted sample finding still a positive coefficient of comparable size that is significant at the $5 \%$ level. Also the regression of column 2 -which mirrors the war incidence regression of column 7 of Table 2 - finds like before in Table 2 a positive coefficient which however is not quite statistically significant. Like before in the columns 9-10 of Table 2, we find in columns 3-4 that the interaction terms of $R_{1} / R$ and group concentration, resp. distance from capital are statistically significant at the $1 \%$ level.

The columns 5-6 re-run the main regressions of columns 2 and 7 of Table 2, but this time for 


\begin{tabular}{|c|c|c|c|c|c|c|c|c|c|c|}
\hline Dep. Var.: Civil War & Onsets & Onsets & Onsets & Onsets & Onsets & Incid. & Incid. & Separ. & Onsets & Onsets \\
\hline & (1) & $(2)$ & (3) & (4) & (5) & (6) & (7) & (8) & (9) & (10) \\
\hline \multirow[t]{2}{*}{ R1 / R } & $0.027 * *$ & $0.022 *$ & $0.064 *$ & $2.610 * * *$ & $3.189 *$ & $0.021 *$ & 0.048 & $0.126 *$ & 0.024 & -0.061 \\
\hline & $(0.012)$ & $(0.012)$ & $(0.033)$ & $(0.652)$ & (1.859) & $(0.012)$ & $(0.034)$ & $(0.074)$ & $(0.026)$ & $(0.047)$ \\
\hline \multirow{2}{*}{ (R1/R)* Group. Conc. } & & & & & & & & & $0.181 * * *$ & \\
\hline & & & & & & & & & $(0.044)$ & \\
\hline \multirow[t]{2}{*}{ (R1/R) * Dist. } & & & & & & & & & & $0.169 * *$ \\
\hline & & & & & & & & & & $(0.068)$ \\
\hline \multirow[t]{2}{*}{ Gr.Pop./Gov.Pop.(t-1) } & $0.003^{*}$ & $0.006 * * *$ & $0.012^{* * *}$ & $0.578 * * *$ & $9.627^{* *}$ & $0.007^{* * *}$ & $0.006 * *$ & 0.081 & 0.012 & $0.012 * * *$ \\
\hline & $(0.002)$ & $(0.002)$ & $(0.002)$ & $(0.158)$ & $(4.589)$ & $(0.002)$ & $(0.002)$ & $(0.050)$ & $(0.010)$ & $(0.002)$ \\
\hline \multirow[t]{2}{*}{ Gov. Pop. (t-1) } & -0.000 & -0.008 & 0.004 & -1.012 & 0.921 & -0.009 & 0.007 & -0.251 & 0.042 & 0.004 \\
\hline & $(0.001)$ & $(0.009)$ & $(0.007)$ & $(2.365)$ & $(3.476)$ & $(0.006)$ & $(0.008)$ & $(0.250)$ & $(0.054)$ & $(0.007)$ \\
\hline \multirow[t]{2}{*}{ Group Peace Duration } & $-0.001 * * *$ & -0.001 & 0.001 & $-0.062 * * *$ & $0.110 * * *$ & & & & 0.001 & 0.001 \\
\hline & $(0.000)$ & $(0.001)$ & $(0.001)$ & $(0.008)$ & $(0.018)$ & & & & $(0.001)$ & $(0.001)$ \\
\hline \multirow[t]{2}{*}{ Group Diamond Mines } & 0.032 & 0.029 & & $5.107^{*}$ & & 0.043 & & -0.025 & & \\
\hline & $(0.032)$ & $(0.031)$ & & $(2.931)$ & & $(0.041)$ & & $(0.124)$ & & \\
\hline \multirow[t]{2}{*}{ Group Co-Ethnics } & $-0.001 * *$ & -0.000 & & -0.014 & & -0.000 & & -0.011 & & \\
\hline & $(0.000)$ & $(0.000)$ & & $(0.065)$ & & $(0.000)$ & & $(0.015)$ & & \\
\hline \multirow[t]{2}{*}{ Group Mount. Terr. } & 0.002 & $0.003^{*}$ & & 0.583 & & 0.002 & & 0.029 & & \\
\hline & $(0.002)$ & $(0.002)$ & & $(0.391)$ & & $(0.002)$ & & $(0.048)$ & & \\
\hline \multirow[t]{2}{*}{ In Group Dist. Cap. } & 0.002 & 0.004 & & $1.325 * * *$ & & $0.006 * *$ & & $0.089 * *$ & & \\
\hline & $(0.001)$ & $(0.002)$ & & $(0.232)$ & & $(0.003)$ & & $(0.039)$ & & \\
\hline \multirow[t]{2}{*}{ Group Soil Quality } & $0.005^{*}$ & 0.001 & & 0.028 & & -0.001 & & 0.074 & & \\
\hline & $(0.002)$ & $(0.002)$ & & $(0.496)$ & & $(0.002)$ & & $(0.076)$ & & \\
\hline \multirow[t]{2}{*}{ Group Pop. Dens. } & 0.009 & 0.014 & & $3.058 * *$ & & 0.023 & & 0.522 & & \\
\hline & $(0.012)$ & $(0.012)$ & & $(1.227)$ & & $(0.015)$ & & (0.399) & & \\
\hline \multirow[t]{2}{*}{ Group War Inc.(t-1) } & & & & & & $0.906 * * *$ & $0.801 * * *$ & & & \\
\hline & & & & & & $(0.014)$ & $(0.030)$ & & & \\
\hline Model & OLS & OLS & OLS & Logit & Logit & OLS & OLS & OLS & OLS & OLS \\
\hline Fixed effects & No & Cou. FE & Gr. FE & Cou. FE & Gr. FE & Cou. FE & Gr. FE & Cou. FE & Gr. FE & Gr. FE \\
\hline Observations & 28549 & 28594 & 28594 & 14799 & 2013 & 30164 & 30164 & 10282 & 11828 & 28594 \\
\hline R-squared & 0.024 & 0.049 & 0.168 & 0.274 & 0.376 & 0.869 & 0.878 & 0.873 & 0.128 & 0.169 \\
\hline \multicolumn{11}{|c|}{$\begin{array}{l}\text { Notes: Dependent variable: Civil war onsets (unless } \\
\text { groups for which observations are available: } 930 \text {. In } \\
\text { to be clustered at the country level (unless in the co } \\
\text { Significance levels: } * p<0.1, * * p<0.05, * * * p<0.01 \text {. }\end{array}$} \\
\hline
\end{tabular}

Table 2: Ethnic Group Level Regressions of the Effect of Oil Unevenness on Conflict Onsets

governing rather than for non-governing groups. According to our theory the expression $R_{2} / R$ that captures resource abundance of the governing group should -if anything-decrease the risk of civil war. We find indeed a negative coefficient which is however imprecisely estimated and not statistically significant. This is unsurprising given the smaller sample size. Still, running such a regression on a sample of governing groups and finding a non significant coefficient of interest being of opposite, negative sign alleviates concerns that our main results could be driven by some other channel outside our model which mechanically leads to more conflict in resource rich groups. 


\section{Conclusion}

This paper has proposed a simple model to capture how the geographical distribution of natural resources within a country can affect the risk of civil war of different types. We have allowed for uneven resource abundance and two different forms of conflict, secessionist and all-out, and found that bargaining fails to prevent costly conflict if an ethnic minority group is located in a region that is particularly rich in natural resources (relative to the rest of the country) and if its winning probability for the case of secessionist conflict is substantially larger than for all-out conflict. This leads to the presence of two relevant threat points for war, which cannot be addressed at the same time by bargaining.

The new simple theory of bargaining breakdown due to multiple types of civil war is not only interesting per se, in our opinion, but it is also shown to fit nicely with most existing empirical findings and with the estimations on our newly constructed data sets with detailed geographic information about ethnic groups and resources.

The analysis of the conditions under which discovery of new resources in a developing country can lead to development without conflicts is still incomplete. This paper has highlighted the significance of resource concentration and group concentration for civil war, but of course the elimination of the resource curse in terms of violent incentives also requires checking that interstate wars and other forms of violence and discriminations can be avoided. An integrated study of the role of natural resources for violent incentives of all kinds is left as next step in our research agenda.

\section{References}

Alesina, Alberto, Arnaud Devleeschauwer, William Easterly, Sergio Kurlat, and Romain Wacziarg (2003): "Fractionalization", Journal of Economic Growth 8: 155-194.

Alesina, Alberto, Stelios Michalopoulos and Elias Papaioannou (2012): "Ethnic Inequality," NBER working paper 18512 .

Alesina, Alberto and Ekaterina Zhuravskaya (2011): "Segregation and the Quality of Government in a Cross Section of Countries", American Economic Review 101: 1872-1911. 
Basedau, Matthias, and Thomas Richter (2011): "Why Do Some Oil Exporters Experience Civil War But Others Do Not? A Qualitative Comparative Analysis of Net Oil-Exporting Countries", mimeo, German Institute of Global and Area Studies.

Bell, Curtis, and Scott Wolford (2014): "Oil Discoveries, Shifting Power, and Civil Conflict," forthcoming in International Studies Quarterly

Besley, Timothy, and Torsten Persson (2011): "The Logic of Political Violence", Quarterly Journal of Economics 126: 1411-1445.

Boulding, Kenneth (1962): Conflict and defense: A general theory, New York: Harper \& Brothers.

Bruk, Solomon, and V. S. Apenchenko (eds) (1964): Atlas narodov mira [Atlas of the Peoples of the World]. Moscow: Glavnoe Upravlenie Geodezii i Kartografi.

Buhaug, Halvard, Scott Gates, and Päivi Lujala (2009): "Geography, Rebel Capability, and the Duration of Civil Conflict," Journal of Conflict Resolution 53: 544-69.

Caselli, Francesco and Wilbur John Coleman II (2013): "On the Theory of Ethnic Conflict," Journal of the European Economic Association 11: 161-192.

Caselli, Francesco, Massimo Morelli, and Dominic Rohner (2013): "The Geography of Inter State Resource Wars," NBER working paper no. 18978.

Cederman, Lars-Erik, Halvard Buhaug and Jan Ketil Rod (2009): "Ethno-Nationalist Dyads and Civil War : A GIS-Based Analysis," Journal of Conflict Resolution 53: 496-525.

Cederman, Lars-Erik and Luc Girardin (2007): "Beyond Fractionalization: Mapping Ethnicity onto Nationalist Insurgencies," American Political Science Review 101: 173-85.

Collier, Paul and Anke Hoeffler (2004): "Greed and Grievance in Civil War", Oxford Economic Papers 56: 563-95.

Collier, Paul, Anke Hoeffler, and Dominic Rohner (2009): "Beyond Greed and Grievance: Feasibility and Civil War", Oxford Economic Papers 61: 1-27.

Collier, Paul and Dominic Rohner (2008): "Democracy, Development, and Conflict", Journal of the European Economic Association 6: 531-40.

Cotet, Anca M., and Kevin K. Tsui (2013): "Oil and Conflict: What Does the Cross Country Evidence Really Show?", American Economic Journal: Macroeconomics 5: 49-80. 
Dube, Oendrila, and Juan Vargas (2013): "Commodity Price Shocks and Civil Conflict: Evidence from Colombia", Review of Economics Studies 80: 1384-1421.

Esteban, Joan, Laura Mayoral, and Debraj Ray (2012): "Ethnicity and Conflict: An Empirical Investigation," American Economic Review 102: 1310-1342.

Esteban, Joan, Massimo Morelli, and Dominic Rohner (2012): "Strategic Mass Killings," mimeo, IAE, Columbia University, and University of Zurich.

Esteban, Joan and Debraj Ray (2011): "A Model of Ethnic Conflict", Journal of the European Economic Association 9: 496-521.

Fearon, James (1995): "Rationalist Explanations for War," International Organization 49: 379-414.

Fearon, James (2003): "Ethnic and Cultural Diversity by Country", Journal of Economic Growth 8: $195-222$.

Fearon, James (2004): "Why Do Some Civil Wars Last So Much Longer than Others?" Journal of Peace Research 41: 275-301.

Fearon, James (2005): "Primary Commodity Exports and Civil War," Journal of Conflict Resolution 49: 483-507.

Fearon, James and David Laitin (2003): "Ethnicity, Insurgency, and Civil War," American Political Science Review 97: 75-90.

Fischer, Guenther, Freddy Nachtergaele, Sylvia Prieler, Harrij van Velthuizen, Luc Verelst, and David Wiberg (2008): Global Agro-ecological Zones Assessment for Agriculture. IIASA, Laxenburg, Austria and FAO, Rome, Italy.

Gates, Scott (2002): "Recruitment and Allegiance: The Microfoundations of Rebellion", Journal of Conflict Resolution 46: 111-30.

Gilmore, Elisabeth, Nils Petter Gleditsch, Päivi Lujala, and Jan Ketil Rod (2005): "Conflict Diamonds: A New Dataset", Conflict Management and Peace Science 22: 257-292.

Gray, J. Patrick (1999): "A Corrected Ethnographic Atlas", World Cultures 10: 24-85.

Grossman, Herschel and Juan Mendoza (2003): "Scarcity and appropriative competition," European Journal of Political Economy 19: 747-58. 
Gurr, Ted (2000): Peoples Versus States: Minorities at Risk in the New Century, Washington DC: U.S. Institute of Peace Press

Heston, Alan, Robert Summers, and Bettina Aten (2011): "Penn World Table Version 7.0", dataset, Center for International Comparisons of Production, Income and Prices at the University of Pennsylvania, http://pwt.econ.upenn.edu/.

Hodler, Roland (2006): "The curse of natural resources in fractionalized countries," European Economic Review 50: 1367-86.

Horowitz, Donald L. (1985): Ethnic Groups in Conflict, Berkeley: University of California Press.

Huber, John and Laura Mayoral (2013): "Civil Conflict and Three Dimensions of Ethnic Inequality", mimeo, Columbia University.

Humphreys, Macartan (2005): "Natural Resources, Conflict, and Conflict Resolution: Uncovering the Mechanisms," Journal of Conflict Resolution 49: 508-37.

Jackson, Matthew O. and Massimo Morelli (2007): "Political Bias and War," American Economic Review 97: 1353-73.

Jackson, Matthew O. and Massimo Morelli (2011): "The Reasons for War, An Updated Survey," in Handbook on the Political Economy of War, edited by Chris Coyne, Cheltenham UK: Edward Elgar Publishing.

Jervis, Robert (1978): "Cooperation under the Security Dilemma," World Politics 30: 188-189.

Killicoat, Philip (2007): "Weaponomics: The Global Market for Assault Rifles," World Bank Policy Research Working Paper 4202, Washington DC: World Bank.

Koenig, Michael, Dominic Rohner, Mathias Thoenig, and Fabrizio Zilibotti (2014): "Networks in Conflict: Theory and Evidence from Ethnic War in Africa", mimeo, University of Zurich and University of Lausanne.

Le Billon, Philippe (2001): "The political ecology of war: natural resources and armed conflicts," Political Geography 20: 561-584.

Lei, Yu-Hsiang, and Guy Michaels (2011): "Do Giant Oil Field Discoveries Fuel Internal Armed Conflicts?", mimeo, LSE.

Levy, Jack (1987): "Declining Power and the Preventive Motivation for War," World Politics 40: 90-92. 
Lewis, M. Paul (ed.) (2009): Ethnologue: Languages of the World (Sixteenth edition), Dallas, Texas: SIL International.

Lujala, Päivi (2010): "The Spoils of Nature: Armed Civil Conflict and Rebel Access to Natural Resources," Journal of Peace Research 47: 15-28.

Lujala, Päivi, Jan Ketil Rod and Nadja Thieme (2007): "Fighting over Oil: Introducing a New Dataset", Conflict Management and Peace Science 24: 239-56.

Lujala, Päivi, Nils Petter Gleditsch and Elisabeth Gilmore (2005): “A Diamond Curse? Civil War and a Lootable Resource," Journal of Conflict Resolution 49: 538-62.

Martinez, Luis (2013): "Where are the rebels? On the geography of conflict and transnational insurgents" mimeo, LSE.

Miguel, Edward, Shanker Satyanath and Ernest Sergenti (2004): "Economic Shocks and Civil Conflict: An Instrumental Variables Approach", Journal of Political Economy 112: 725-53.

Minorities at Risk (2009): Dataset, www.cidcm.umd.edu/mar.

Montalvo, José and Marta Reynal-Querol (2005): "Ethnic Polarization, Potential Conflict, and Civil Wars," American Economic Review 95: 796-815.

Morelli, Massimo, and Dominic Rohner (2010): "Natural Resource Distribution and Multiple Forms of Civil War," IEW Working Paper 498, Department of Economics, University of Zurich.

Morelli, Massimo and Costantino Pischedda (2014): "The Turkey-KRG Energy Partnership: Assessing Its Implications", Middle East Policy 21(1).

Ploeg, Frederick van der and Dominic Rohner (2012): "War and Natural Resource Exploitation," European Economic Review 56: 1714-1729.

Polity IV, 2012, "Political Regime Characteristics and Transitions", dataset, www.systemicpeace.org/polity 4 .

Powell, Robert (1996): "Uncertainty, Shifting Power, and Appeasement", American Political Science Review 90: 749-764.

Powell, Robert (2006): "War as a Commitment Problem," International Organization 60: 169-203.

Powell, Robert (2013): "Monopolizing Violence and Consolidating Power," Quarterly Journal of Economics 128: 807-859. 
Reiter, Dan (1995): "Exploding the Powder Keg Myth: Preemptive Wars Almost Never Happen," International Security 20: 5-34.

Reuveny, Rafael and John Maxwell (2001): "Conflict and Renewable Resources," Journal of Conflict Resolution 45: 719-42.

Reynal-Querol, Marta (2002): "Ethnicity, Political Systems, and Civil Wars," Journal of Conflict Resolution 46: 29-54.

Rogall, Thorsten (2013): "The Escalation of Violence: Armed Groups and Civilian Perpetrators", mimeo, IIES Stockhom.

Rohner, Dominic, Mathias Thoenig, and Fabrizio Zilibotti (2013): "War Signals: A Theory of Trade, Trust and Conflict," Review of Economic Studies 80: 1114-1147.

Rohner, Dominic, Mathias Thoenig, and Fabrizio Zilibotti (2013b): "Seeds of Distrust: Conflict in Uganda", Journal of Economic Growth 18: 217-252.

Ross, Michael (2004): "What Do We Know About Natural Resources and Civil War?" Journal of Peace Research 41: 337-56.

Ross, Michael (2004b): "How Do Natural Resources Influence Civil War? Evidence from Thirteen Cases," International Organization 58: 35-67.

Saideman, Stephen, David Lanoue, Michael Campenni, and Samuel Stanton (2002): "Democratization, Political Institutions, and Ethnic Conflict: A Pooled Time-Series Analysis, 1985-1998," Comparative Political Studies 35: 103-29.

Salehyan, Idean (2007): "Transnational Rebels: Neighboring States as Sanctuary for Rebel Groups", World Politics 59: 217-242.

Sambanis, Nicholas (2004): "Poverty and the Organization of Political Violence: A Review and Some Conjectures," in Carol Graham and Susan Collins (eds.), Brookings Trade Forum: 2004: Globalization, Poverty, and Inequality, Washington DC: Brookings Institution Press.

Schelling, Thomas C. (1966): Arms and Influence, New Haven and London: Yale University Press. Sedac (2012): "Geo-referenced population density data," Dataset, Socioeconomic Data and Applications Center (Sedac), Columbia University, http://sedac.ciesin.org/.

Snyder, Jack (1984): "Civil-Military Relations and the Cult of the Offensive, 1914 and 1984," International Security 9: 108- 146. 
Taylor, A.J.P. (1954): The Struggle for Mastery in Europe, 1848 to 1918, Oxford: Clarendon Press.

UCDP (2012): "UCDP/PRIO Armed Conflict Dataset," dataset, www.pcr.uu.se/research/ucdp.

Vanden Eynde, Oliver (2011): "Targets of Violence: Evidence from India's Naxalite Conflict", mimeo, Paris School of Economics.

Walter, Barbara (2006): "Information, Uncertainty, and the Decision to Secede," International Organization 60: 105-35.

Walter, Barbara (2006b): "Building Reputation: Why Governments Fight Some Separatists but Not Others, " American Journal of Political Science 50: 313-30.

Weidmann, Nils, Doreen Kuse, and Kristian Skrede Gleditsch (2010): "The Geography of the International System: The CShapes Dataset," International Interactions 36: 86-106.

Weidmann, Nils, Jan Ketil Rod, and Lars-Erik Cederman (2010): "Representing Ethnic Groups in Space: A New Dataset," Journal of Peace Research 47: 491-499

World Bank (2010): "Adjusted Net Savings Database", Dataset, http://go.worldbank.org/3AWKN2ZOY0.

World Bank (2012): "World Development Indicators," Dataset, http://data.worldbank.org/indicator.

Wucherpfennig, Julian, Nils Weidmann, Luc Girardin, Lars-Erik Cederman, and Andreas Wimmer (2011): "Politically relevant ethnic groups across space and time: Introducing the GeoEPR dataset", Conflict Management and Peace Science 28: 423-437.

\section{Appendix A: Characterization of equilibrium}

Define the threshold $\bar{\alpha} \equiv p_{c}+\frac{d_{j}(C)}{R_{1}+R_{2}}$ as an upper bound of government concessions that would still make group $j$ prefer peace to all-out conflict. Group $i$ weakly prefers peace to all-out conflict if $\alpha \geq \underline{\alpha}_{c} \equiv p_{c}-\frac{d_{i}(C)}{R_{1}+R_{2}}$. Note that $\underline{\alpha}_{c}<\bar{\alpha}$ always holds. Hence if only all-out conflict were considered as a possibility, there would be an obvious Pareto frontier of intermediate values of $\alpha$ between these two that would avoid war if the two players could bargain about $\alpha$.

Considering that another type of conflict is possible; group $i$ weakly prefers peace to secessionist conflict if $\alpha \geq \underline{\alpha}_{s} \equiv p_{s} \frac{R_{1}}{R_{1}+R_{2}}-\frac{d_{i}(S)}{R_{1}+R_{2}}$. We restrict attention to the most interesting setting where $\underline{\alpha}_{c}>0, \underline{\alpha}_{s}>0$. There are three cases to consider (recall that $\theta=$ probability that group $j$ can 
impose all-out war in the face of a secessionist rebellion). In terms of notation, $(x, y)$ means that $i$ plays $x$ and $j$ plays $y$.

Note first that this game features multiple equilibria. In particular, a bad equilibrium with conflict always exists. This is intuitive, as it takes two for peace, and hence if a given player plays $c$ or $s$, then the opponent can never achieve peace, hence either $(c, c)$ or $(s, c)$ is always an equilibrium.

Below, we will characterize the best SPE that can be sustained.

Case $1\left(\bar{\alpha}>\underline{\alpha}_{c}>\underline{\alpha}_{s}>0\right)$ :

The only two possible rent-sharing choices have the following consequences: $\alpha=0 \Rightarrow(c,\{p, c\})$, $\alpha=\underline{\alpha}_{c} \Rightarrow(p, p)$.

$$
\begin{gathered}
E\left(\pi^{j}(\alpha=0)\right)=\left(1-p_{c}\right)\left(R_{1}+R_{2}\right)-d_{j}(C), \\
E\left(\pi^{j}\left(\alpha=\underline{\alpha}_{c}\right)\right)=\left(1-\underline{\alpha}_{c}\right)\left(R_{1}+R_{2}\right)=\left(1-p_{c}\right)\left(R_{1}+R_{2}\right)+d_{i}(C) .
\end{gathered}
$$

Group $j$ would always select $\alpha=\underline{\alpha}_{c}$, followed by peace in the best SPE.

Case $2 a\left(\bar{\alpha}>\underline{\alpha}_{s}>\underline{\alpha}_{c}>0\right.$ and $\pi_{S}^{j}>\pi_{C}^{j}$ (which can happen when $\left.\left.d_{j}(S)<<d_{j}(C)\right)\right)$ :

The only two possible rent-sharing choices have the following consequences: $\alpha=0 \Rightarrow(s, p)$, $\alpha=\underline{\alpha}_{s} \Rightarrow(p, p)$.

$$
\begin{gathered}
E\left(\pi^{j}(\alpha=0)\right)=\left(1-p_{s}\right) R_{1}+R_{2}-d_{j}(S), \\
E\left(\pi^{j}\left(\alpha=\underline{\alpha}_{s}\right)\right)=\left(1-\underline{\alpha}_{s}\right)\left(R_{1}+R_{2}\right)=\left(1-p_{s}\right) R_{1}+R_{2}+d_{i}(S) .
\end{gathered}
$$

Group $j$ would always select $\alpha=\underline{\alpha}_{s}$, followed by peace in the best SPE.

Case $2 b\left(\bar{\alpha}>\underline{\alpha}_{s}>\underline{\alpha}_{c}>0\right.$ and $\left.\pi_{S}^{j}<\pi_{C}^{j}\right)$ :

The only two possible rent-sharing choices have the following consequences: $\alpha=0 \Rightarrow(s, c)$, $\alpha=\underline{\alpha}_{s} \Rightarrow(p, p)$.

$$
\begin{gathered}
E\left(\pi^{j}(\alpha=0)\right)=\theta\left[\left(1-p_{c}\right)\left(R_{1}+R_{2}\right)-d_{j}(C)\right]+(1-\theta)\left[\left(1-p_{s}\right) R_{1}+R_{2}-d_{j}(S)\right] \\
E\left(\pi^{j}\left(\alpha=\underline{\alpha}_{s}\right)\right)=\left(1-\underline{\alpha}_{s}\right)\left(R_{1}+R_{2}\right)=\left(1-p_{s}\right) R_{1}+R_{2}+d_{i}(S) .
\end{gathered}
$$


Group $j$ will select $\alpha=\underline{\alpha}_{s}$ iff the following condition holds (and $\alpha=0$ otherwise):

$$
\theta\left[\left(1-p_{c}\right)\left(R_{1}+R_{2}\right)-d_{j}(C)-\left(1-p_{s}\right) R_{1}-R_{2}+d_{j}(S)\right]<d_{i}(S)+d_{j}(S) .
$$

This always holds when $\theta$ is small. It is again possible in this case to have a peaceful outcome as best SPE.

Case $3 a\left(\underline{\alpha}_{s}>\bar{\alpha}>\underline{\alpha}_{c}>0\right.$ and $\left.\pi_{S}^{j}>\pi_{C}^{j}\right)$ :

The only two possible rent-sharing choices have the following consequences: $\alpha=0 \Rightarrow(s, p)$, $\alpha=\underline{\alpha}_{s} \Rightarrow(s, p)$. Hence, group $j$ will be indifferent between $\alpha=0$ and $\alpha=\underline{\alpha}_{s}$. In case 3a for both $\alpha=0$ or $\alpha=\underline{\alpha}_{s}$ there will always be secessionist conflict.

Case $3 b\left(\underline{\alpha}_{s}>\bar{\alpha}>\underline{\alpha}_{c}>0\right.$ and $\left.\pi_{S}^{j}<\pi_{C}^{j}\right)$ :

The only two possible rent-sharing choices have the following consequences: $\alpha=0 \Rightarrow(s, c)$, $\alpha=\underline{\alpha}_{s} \Rightarrow(s, c)$. Hence, group $j$ is indifferent between selecting $\alpha=\underline{\alpha}_{s}$ or $\alpha=0$, which both result in the same outcome. There will always be conflict in case $3 \mathrm{~b}$ (in particular, with probability $\theta$ there will be all-out conflict, while with probability $(1-\theta)$ there will be secessionist conflict).

To sum up, in the third case (cases 3a and 3b), where $\underline{\alpha}_{s}>\bar{\alpha}$, even in the best SPE no surplus sharing can avoid conflict.

\section{Appendix B: Additional Regression Tables}

The Tables 3 and 4 display -as discussed in the main text- additional regressions at the country, resp. ethnic group level.

\section{Appendix C: Data}

This appendix describes the data used in section 3. Table 5 provides the descriptive summary statistics for all variables.

\section{Country Level Variables}

The dependent variables, civil war onset and incidence, and the main independent variable, Oil Gini, have been described above in the main text. In what follows we describe the control variables.

Oil exporter: Dummy variable taking a value of 1 if in a given country and year the fuel exports (in \% of merchandise exports) is above 33\%. Variable from Fearon and Laitin (2003), but updated with recent data of the variable "fuel exports (in \% of merchandise exports)" from World Bank (2012). 


\begin{tabular}{|c|c|c|c|c|c|c|}
\hline & \multicolumn{6}{|c|}{ Dependent variable: Civil War Onsets } \\
\hline & (1) & $(2)$ & (3) & (4) & (5) & (6) \\
\hline \multirow[t]{2}{*}{ Oil Gini } & $0.069 *$ & $0.107 * *$ & $0.067 *$ & $0.092^{*}$ & $0.155^{* *}$ & $0.083^{*}$ \\
\hline & $(0.037)$ & $(0.053)$ & $(0.037)$ & $(0.053)$ & $(0.067)$ & $(0.049)$ \\
\hline \multirow[t]{2}{*}{ Oil exporter (t-1) } & 0.020 & 0.033 & & 0.029 & 0.017 & -0.008 \\
\hline & $(0.019)$ & $(0.021)$ & & $(0.044)$ & $(0.026)$ & (0.009) \\
\hline \multirow[t]{2}{*}{ In GDP p.c.(t-1) } & -0.004 & 0.000 & $-0.017 *$ & -0.005 & -0.006 & -0.009 \\
\hline & $(0.009)$ & $(0.012)$ & $(0.010)$ & $(0.018)$ & $(0.029)$ & $(0.019)$ \\
\hline \multirow[t]{2}{*}{ Democ. $(t-1)$} & -0.001 & -0.001 & -0.001 & $-0.002 * * *$ & -0.001 & $-0.002 * * *$ \\
\hline & $(0.001)$ & $(0.001)$ & $(0.001)$ & $(0.001)$ & $(0.001)$ & $(0.001)$ \\
\hline \multirow[t]{2}{*}{ In Popul.(t-1) } & 0.008 & 0.011 & 0.021 & 0.004 & -0.007 & -0.007 \\
\hline & $(0.012)$ & $(0.016)$ & $(0.015)$ & $(0.026)$ & $(0.028)$ & $(0.024)$ \\
\hline \multirow[t]{2}{*}{ New State } & 0.011 & 0.000 & $0.014 *$ & -0.003 & 0.011 & -0.002 \\
\hline & $(0.008)$ & $(0.006)$ & $(0.007)$ & $(0.013)$ & $(0.013)$ & $(0.013)$ \\
\hline \multirow[t]{2}{*}{ War yrs. last 5y. } & $0.017^{*}$ & & & & & \\
\hline & $(0.009)$ & & & & & \\
\hline \multirow[t]{2}{*}{ Gold Producer } & & -0.024 & & & & \\
\hline & & $(0.020)$ & & & & \\
\hline \multirow[t]{2}{*}{ Diamond Producer } & & -0.039 & & & & \\
\hline & & $(0.027)$ & & & & \\
\hline \multirow[t]{2}{*}{ Peace duration } & & -0.000 & -0.000 & -0.001 & & -0.001 \\
\hline & & $(0.001)$ & $(0.001)$ & $(0.001)$ & & $(0.001)$ \\
\hline \multirow[t]{2}{*}{ Oil Prod. pc. (t-1) } & & & 0.034 & & & \\
\hline & & & $(0.029)$ & & & \\
\hline \multirow[t]{2}{*}{ Civ. War Incid. (t-1) } & & & & & $0.556 * * *$ & \\
\hline & & & & & $(0.051)$ & \\
\hline \multirow[t]{2}{*}{ Oil Exp. * Oil Gini } & & & & & & $1.394 * * *$ \\
\hline & & & & & & $(0.071)$ \\
\hline Sample & \multicolumn{3}{|c|}{ All countries } & \multicolumn{3}{|c|}{ All countries without oil in 1964} \\
\hline Model & OLS & OLS & OLS & OLS & OLS & OLS \\
\hline Country Fixed Eff. & Yes & Yes & Yes & Yes & Yes & Yes \\
\hline Observations & 4949 & 4017 & 4204 & 1918 & 2035 & 1918 \\
\hline R-squared & 0.117 & 0.137 & 0.125 & 0.125 & 0.521 & 0.141 \\
\hline
\end{tabular}

Notes: Dependent variable: Civil war onset (unless in column 5 where the dependent variable is Conflict incidence). The dependent variable is coded as 1 if a conflict causing at least 1000 fatalities is starting in a given year. Sample period: 1960-2008. Number of countries for which observations are available: 157. In all columns unreported country fixed effects and annual time dummies are included, and robust standard errors are allowed to be clustered at the country level. Significance levels: ${ }^{*} p<0.1,{ }^{* *} p<0.05,{ }^{* * *} p<0.01$.

Table 3: Additional Country Level Regressions of the Effect of Oil Gini on Conflict Onsets 


\begin{tabular}{|c|c|c|c|c|c|c|}
\hline Dep. Var.: Civil War & Onsets & Incid. & Onsets & Onsets & Onsets & Incid. \\
\hline & $(1)$ & $(2)$ & (3) & (4) & (5) & (6) \\
\hline \multirow{2}{*}{ R1 / R } & $0.096 * *$ & 0.041 & 0.032 & -0.035 & -0.004 & -0.019 \\
\hline & $(0.044)$ & $(0.034)$ & $(0.023)$ & $(0.026)$ & $(0.008)$ & $(0.014)$ \\
\hline \multirow[t]{2}{*}{ (R1/R)* Group. Conc. } & \multirow{2}{*}{\multicolumn{6}{|c|}{$\begin{array}{c}0.184 * * * \\
(0.027)\end{array}$}} \\
\hline & & & & & & \\
\hline \multirow[t]{2}{*}{ (R1/R) * Dist. } & & & & $0.173 * *$ & & \\
\hline & & & & $(0.066)$ & & \\
\hline \multirow[t]{2}{*}{ Gr.Pop./Gov.Pop.(t-1) } & 0.010 & 0.004 & 0.015 & 0.010 & -0.021 & $-0.052 * * *$ \\
\hline & $(0.008)$ & $(0.006)$ & $(0.013)$ & $(0.008)$ & $(0.014)$ & $(0.010)$ \\
\hline \multirow[t]{2}{*}{ Gov. Pop. (t-1) } & -0.006 & 0.049 & 0.067 & -0.006 & -0.038 & $-0.118 * * *$ \\
\hline & $(0.017)$ & $(0.056)$ & $(0.067)$ & $(0.017)$ & $(0.023)$ & $(0.041)$ \\
\hline \multirow[t]{2}{*}{ Group Peace Duration } & 0.002 & & $0.003^{* *}$ & 0.002 & 0.000 & \\
\hline & $(0.001)$ & & $(0.001)$ & $(0.001)$ & $(0.001)$ & \\
\hline \multirow[t]{2}{*}{ Group War Inc.(t-1) } & & $0.845^{* * *}$ & & & & $0.722 * * *$ \\
\hline & & $(0.032)$ & & & & $(0.064)$ \\
\hline Sample & \multicolumn{4}{|c|}{ Non-gov. groups in countries without oil in 1964} & \multicolumn{2}{|c|}{ Governing groups } \\
\hline Model & OLS & OLS & OLS & OLS & OLS & OLS \\
\hline Group fixed effects & Yes & Yes & Yes & Yes & Yes & Yes \\
\hline Observations & 9616 & 10533 & 3431 & 9616 & 8383 & 8538 \\
\hline R-squared & 0.203 & 0.898 & 0.227 & 0.204 & 0.175 & 0.794 \\
\hline \multicolumn{7}{|c|}{$\begin{array}{l}\text { Notes: Dependent variable: Civil war onsets (unless when specified differently in row } 1 \text { ). Sample period: } \\
\text { 1960-2006. Number of ethnic groups for which observations are available: max. } 317 \text { for columns } 1-4 ; \\
273 \text { for columns } 5-6 \text {. In all columns unreported group fixed effects and annual time dummies are } \\
\text { included, and robust standard errors are allowed to be clustered at the country level. Significance } \\
\text { levels: }{ }^{*} p<0.1, * * p<0.05, * * * p<0.01 \text {. }\end{array}$} \\
\hline
\end{tabular}

Table 4: Additional Ethnic Group Level Regressions of the Effect of Oil Unevenness on Conflict Onsets 
In GDP per capita: PPP adjusted GDP per capita at constant prices. From the Penn World Tables (Heston, Summers, and Aten, 2011).

Democracy: Polity scores ranging from -10 (strongly autocratic) to +10 (strongly democratic). From Polity IV (2012).

In Population: Total population. From World Bank (2012).

New State: Coded as 1 when a state was created in the previous 10 years, coded as 0 otherwise.

Ethnic Fractionalization: Index of ethnic fractionalization. From Fearon and Laitin (2003).

Mountainous Terrain: Percentage of territory covered by mountains. From Collier, Hoeffler and Rohner (2009).

Noncontiguous State: Dummy taking a value of 1 if a state has noncontiguous territory. From Fearon and Laitin (2003).

Peace duration: Years since last civil war incidence.

Conflict Incidence (t-1): First lag of the civil war incidence variable.

War years during last 5 years: Count of how many civil war incidence years during last 5 years, ranging from 0 to 5 .

Gold Production Dummy: Takes a value of 1 when there is gold production in a country year, and 0 otherwise. From World Bank (2010).

Diamonds production dummy: Takes a value of 1 when there is diamond production in a country year, and 0 otherwise. From Lujala, Gleditsch, and Gilmore (2005).

Oil production per capita: Average amount per capita of oil extracted per day in a given year, measured in millions of barrels per day. From Humphreys (2005).

Oil exporter * Oil Gini: Interaction term of the variables Oil exporter and Oil Gini defined above.

\subsection{Group Level Variables}

The two main dependent variables, civil war onset and incidence at the group level, and the main independent variable, $R_{1} / R$, have been described above in the main text. In what follows we describe the third dependent variable and all control variables.

Separatism: Dummy taking a value of 1 when the variable Sepx from Minorities at Risk (2009) takes a value of 2 or above.

Group Population / Governing Groups' Population: From Cederman, Buhaug and Rod (2009). Note that the population estimates of each ethnic group are not time-varying, but that the composition of groups controlling the government is time varying, which makes this measure time 
varying.

Governing Groups' Population: In 100 Millions. From Cederman, Buhaug and Rod (2009). The population estimates of each ethnic group are not time-varying, but that the composition of groups controlling the government is time varying, which makes this measure time varying.

Group Peace Duration: Years since last civil war incidence involving the given ethnic group.

Group Diamond Mines: Total number of diamond mines on the group territory (re-scaled in 100 mines). Constructed with GIS based on the group boundaries from the "Geo-referencing of ethnic groups" (GREG) dataset (Weidmann, Rod and Cederman, 2010) and the geo-referenced DIADATA dataset on the location of diamonds (from Gilmore et al., 2005).

Group co-ethnics abroad: Number of countries in which the same ethnic group also exists. Computed with GIS based on the group boundaries from the "Geo-referencing of ethnic groups" (GREG) dataset (Weidmann, Rod and Cederman, 2010).

Group's share of mountainous terrain: From Cederman, Buhaug and Rod (2009).

In group's distance to capital: From Cederman, Buhaug and Rod (2009).

Group's soil quality: Part of the group's territory with high-quality fertile soil. Constructed based on the Harmonized World Soil Database (Fischer et al., 2008). Their complete global grid of nutrient availability is ranked from 1 ("no or slight constraints") to 4 ("very severe constraints"), and also including categories 5 ("mainly non-soil"), 6 ("permafrost area") and 7 ("water bodies"). Our dummy takes a value of 1 for categories 1 and 2, categories 3 to 6 get value 0 , and category 7 is set to missing.

Group Population Density: Average population density, re-scaled in 1000, constructed with GIS based on the on the group boundaries from the "Geo-referencing of ethnic groups" (GREG) dataset (Weidmann, Rod and Cederman, 2010) and the geo-referenced population density data from the Socioeconomic Data and Applications Center at Columbia University (Sedac, 2012).

Group War Incidence (t-1): First lag of the group level civil war incidence variable.

$(R 1 / R) *$ Group Concentration: Interaction term between the $(\mathrm{R} 1 / \mathrm{R})$ variable and the following group concentration measure. The group concentration variable corresponds to the ratio of the "ethnic group's population living in areas where this ethnic group is the largest group" divided by the "total population of an ethnic group" in a given country. This time-invariant variable has been constructed using raw data from Alesina and Zhuravskaya (2011).

$(R 1 / R) *$ Distance: Interaction term between the $(\mathrm{R} 1 / \mathrm{R})$ variable and a dummy variable taking a value of 1 if the value of the group distance from capital variable described above is larger than its median. 


\begin{tabular}{|c|c|c|c|c|c|}
\hline Country Level Variables & Obs & Avg & $\mathrm{Sd}$ & Min & Max \\
\hline Conflict Onset & 8071 & 0.015 & 0.123 & 0 & 1 \\
\hline Conflict Incidence & 8494 & 0.050 & 0.219 & 0 & 1 \\
\hline Oil Gini & 7983 & 0.167 & 0.258 & 0 & 0.977 \\
\hline Oil Exp. * Oil Gini & 7464 & 0.038 & 0.145 & 0 & 0.888 \\
\hline Oil exporter (t-1) & 7775 & 0.139 & 0.346 & 0 & 1 \\
\hline Gold Producer & 6277 & 0.389 & 0.488 & 0 & 1 \\
\hline Diamond Producer & 7921 & 0.186 & 0.389 & 0 & 1 \\
\hline Oil Prod. pc. (t-1) & 5237 & 0.045 & 0.270 & 0 & 4.923 \\
\hline In GDP p.c.(t-1) & 7074 & 8.249 & 1.287 & 4.767 & 11.722 \\
\hline Democ. $(t-1)$ & 7662 & 0 & 7.666 & -10 & 10 \\
\hline In Popul.(t-1) & 7059 & 15.747 & 1.680 & 11.578 & 21.000 \\
\hline New State & 8494 & 0.126 & 0.332 & 0 & 1 \\
\hline Ethnic Fraction. & 7921 & 0.392 & 0.284 & 0.001 & 0.925 \\
\hline Mountainous Terr. & 7559 & 0.176 & 0.209 & 0 & 0.943 \\
\hline Noncontig. State & 7921 & 0.169 & 0.375 & 0 & 1 \\
\hline Peace duration & 8428 & 29.452 & 18.781 & 0 & 62 \\
\hline Conflict Incid. (t-1) & 8428 & 0.050 & 0.218 & 0 & 1 \\
\hline Conflict yrs. last 5y. & 7613 & 0.257 & 0.920 & 0 & 5 \\
\hline Group Level Variables & Obs & Avg & $\mathrm{Sd}$ & Min & Max \\
\hline Group Conflict Onset & 63869 & 0.003 & 0.059 & 0 & 1 \\
\hline Group Conflict Incid. & 65934 & 0.035 & 0.183 & 0 & 1 \\
\hline Group Separatism & 19313 & 0.336 & 0.472 & 0 & 1 \\
\hline $\mathrm{R} 1 / \mathrm{R}$ & 69596 & 0.065 & 0.210 & 0 & 1 \\
\hline (R1/R)* Group. Conc. & 28987 & 0.059 & 0.210 & 0 & 1 \\
\hline$(\mathrm{R} 1 / \mathrm{R})$ * Dist. & 65934 & 0.018 & 0.102 & 0 & 1 \\
\hline Gr.Pop./Gov.Pop.(t-1) & 55884 & 0.165 & 0.441 & $7.80 \mathrm{E}-08$ & 8.918 \\
\hline Gov. Pop. (t-1) & 55884 & 0.686 & 1.564 & 0.001 & 8.673 \\
\hline Group Peace Duration & 63869 & 25.610 & 16.330 & 0 & 59 \\
\hline Group Diamond Mines & 69596 & 0.006 & 0.061 & 0 & 1.790 \\
\hline Group Co-Ethnics & 69596 & 2.781 & 2.329 & 1 & 15 \\
\hline Group Mount. Terr. & 65934 & 0.369 & 0.352 & 0 & 1 \\
\hline In Group Dist. Cap. & 65934 & 6.154 & 1.090 & 1.609 & 8.782 \\
\hline Group Soil Quality & 69596 & 0.699 & 0.333 & 0 & 1 \\
\hline Group Pop. Dens. & 69596 & 0.069 & 0.153 & 0 & 4.354 \\
\hline Group Conflict Inc.(t-1) & 65880 & 0.035 & 0.183 & 0 & 1 \\
\hline
\end{tabular}

Table 5: Descriptive Statistics 